The Oak Ridge Institute for Science and Education (ORISE) is a U.S. Department of Energy facility focusing on scientific initiatives to research health risks from occupational hazards, assess environmental cleanup, respond to radiation medical emergencies, support national security and emergency preparedness, and educate the next generation of scientists. ORISE is managed by Oak Ridge Associated Universities. Established in 1946, ORAU is a consortium of 99 colleges and universities.

\section{NOTICES}

The opinions expressed herein do not necessarily reflect the opinions of the sponsoring institutions of Oak Ridge Associated Universities.

This report was prepared as an account of work sponsored by the United States Government. Neither the United States Government nor the U.S. Department of Energy, nor any of their employees, makes any warranty, expressed or implied, or assumes any legal liability or responsibility for the accuracy, completeness, or usefulness of any information, apparatus, product, or process disclosed, or represents that its use would not infringe on privately owned rights. Reference herein to any specific commercial product, process, or service by trade name, mark, manufacturer, or otherwise, does not necessarily constitute or imply its endorsement or recommendation, or favor by the U.S. Government or any agency thereof. The views and opinions of authors expressed herein do not necessarily state or reflect those of the U.S. Government or any agency thereof. 


\title{
VERIFICATION SURVEY OF THE BUILDING 4059 SITE (PHASE B); POST HISTORICAL SITE ASSESSMENT SITES, BLOCK 1; and RADIOACTIVE MATERIALS HANDLING FACILITY HOLDUP POND (SITE 4614) SANTA SUSANA FIELD LABORATORY THE BOEING COMPANY VENTURA COUNTY, CALIFORNIA
}

\author{
Prepared by \\ T. J. Vitkus \\ Independent Environmental Assessment and Verification Program \\ Oak Ridge Institute for Science and Education \\ Oak Ridge, Tennessee 37831-0017 \\ Prepared for the \\ U.S. Department of Energy
}

FINAL REPORT

JUNE 2008

This report is based on work performed by the Oak Ridge Institute for Science and Education Under contract number DE-AC05-06OR23100 with the Department of Energy 


\section{VERIFICATION SURVEY OF THE \\ BUILDING 4059 SITE (PHASE B); \\ POST HISTORICAL SITE ASSESSMENT SITES, BLOCK 1; and \\ RADIOACTIVE MATERIALS HANDLING FACILITY \\ HOLDUP POND (SITE 4614) SANTA SUSANA FIELD LABORATORY \\ THE BOEING COMPANY \\ VENTURA COUNTY, CALIFORNIA}

Prepared by:

Reviewed by: R. A. Concha

R. D. Condra, Laboratory Manager

Independent Environmental Assessment and Verification

Date: $6 / 4 / 08$

Date: $6 / 3 / 2008$

Reviewed by: Juesayskon (for)

A. T. Payne, Quality Manager

Independent Environmental Assessment and Verification

Date: $6 / 4 / 08$

Reviewed by:

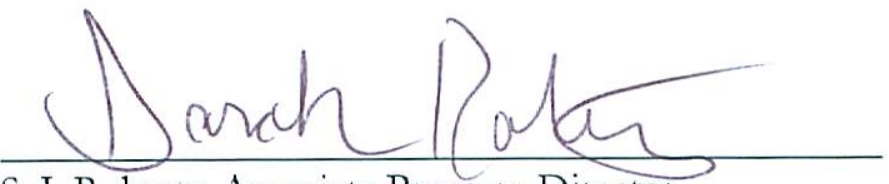

S. J. Roberts, Associate Program Director

Independent Environmental Assessment and Verification

Date: $6 / 3 / 08$ 


\title{
ACKNOWLEDGMENTS
}

The author would like to acknowledge the significant contributions of the following staff members:

FIELD AND SUPPORT STAFF

E. N. Bailey

T. D. Herrera

E. Montalvo

\section{LABORATORY STAFF}

R. D. Condra

J. S. Cox

W. P. Ivey

W. F. Smith

\section{CLERICAL STAFF}

R. M. Fink

K. M. Moore

A. Ramsey

\section{ILLUSTRATORS}

\author{
T. D. Herrera \\ J. A. Viars
}




\section{TABLE OF CONTENTS}

PAGE

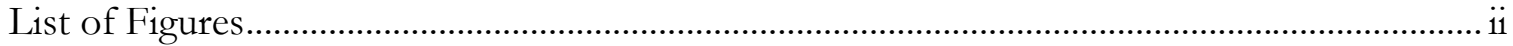

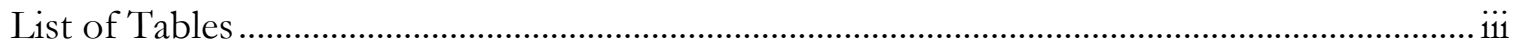

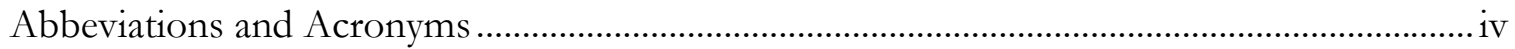

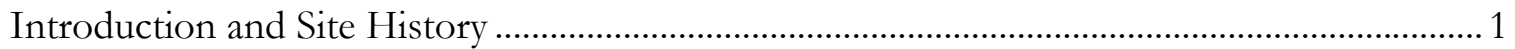

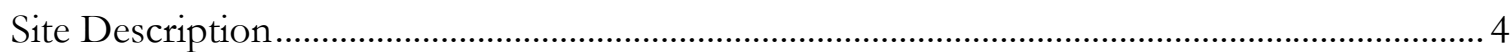

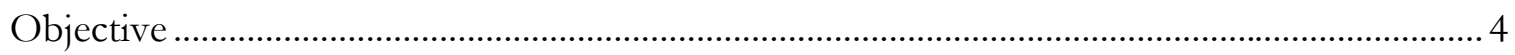

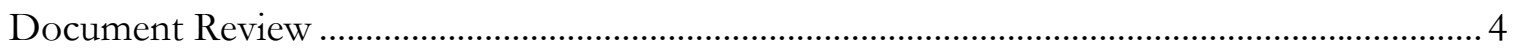

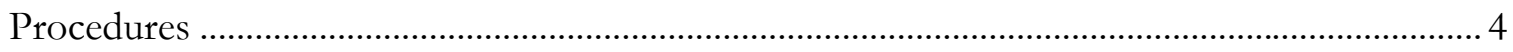

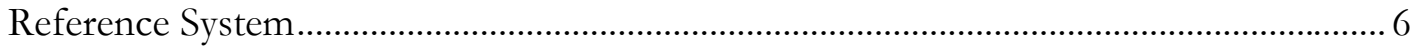

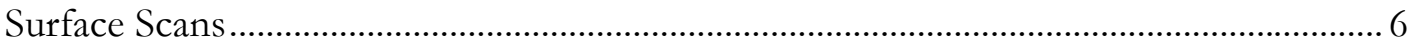

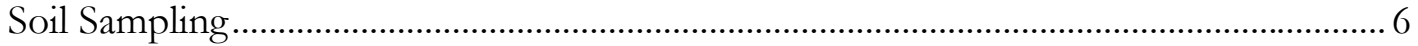

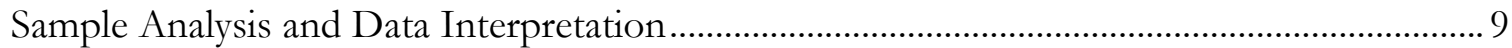

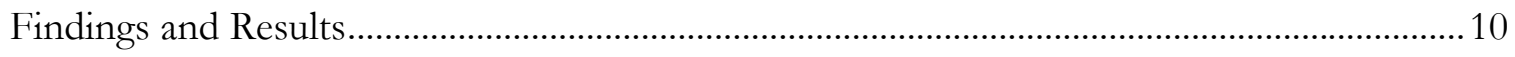

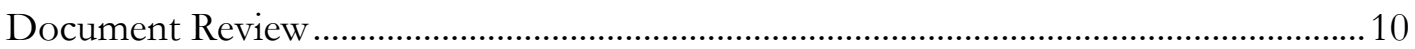

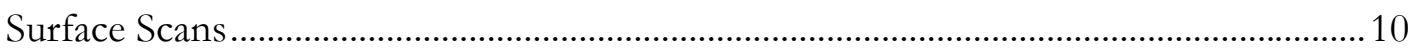

Radionuclide Concentrations in Soil Samples ................................................................. 10

Comparison of Results With Release Criteria................................................................................11

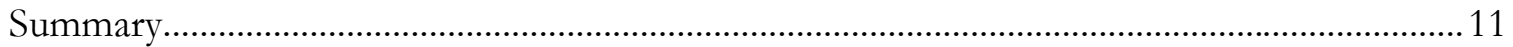

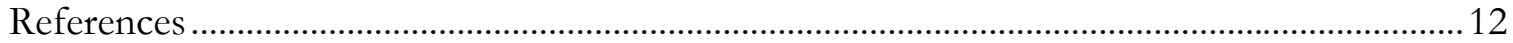

Appendices:

Appendix A: Figures

Appendix B: Tables

Appendix C: Major Instrumentation

Appendix D: Survey And Analytical Procedures 


\section{LIST OF FIGURES}

Figure 1: Example Land Area Unit With Ranked Set Sampling Locations............................................

Figure A-1: Location of the Santa Susana Field Laboratory (SSFL) .................................................. A-1

Figure A-2: Santa Susana Field Laboratory, Area IV_-Plot Plan ....................................................... A-2

Figure A-3: Santa Susana Field Laboratory, Area IV—Survey Areas and Survey Unit

Classifications

Figure A-4: Group 1 Verification Population, Survey Areas-Ranked Set Sampling Measurement

Locations....

Figure A-5: Group 2 Verification Population, Survey Areas-Ranked Set Sampling Measurement

Locations. A-5

Figure A-6: Group 1 Verification Population, Survey Areas-Soil Sampling Locations .................. A-6

Figure A-7: Group 2 Verification Population, Survey Areas—Soil Sampling Locations .................. A-7

Figure A-8: Area 4023—Survey Area and Gamma Scans ............................................................ A-8

Figure A-9: Area 4028—-Survey Area and Gamma Scans ............................................................. A-9

Figure A-10: Area 4030—Survey Area and Gamma Scans ........................................................... A-10

Figure A-11: Area 4363—Survey Area and Gamma Scans ............................................................ A-11

Figure A-12: Area 4614—Survey Area and Gamma Scans .............................................................. A-12

Figure A-13: Area 4059—Survey Area and Gamma Scans ............................................................ A-13

Figure A-14: Area 4583—Survey Area and Gamma Scans .............................................................. A-14

Figure A-15: Verification Gamma Scan Count Rate Histogram (Combined Data) ........................ A-15 


\section{LIST OF TABLES}

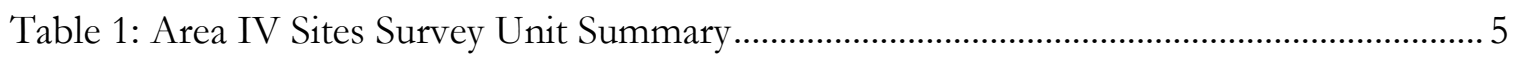

Table 2: Radionuclide Concentrations in Soil Samples Summary Results ...............................11

Table B-1: Ranked Set Sampling Gamma Measurements ........................................................ B-1

Table B-2: Radionuclide Concentrations in Soil Samples ....................................................... B-3

Table B-3: Soil Guideline Release Limits .................................................................................. B-4 


\section{ABBREVIATIONS AND ACRONYMS}

$\begin{array}{ll}\text { AEC } & \text { Atomic Energy Commission } \\ \text { BKG } & \text { background } \\ \text { cm } & \text { centimeter } \\ \text { cpm } & \text { counts per minute } \\ \text { D\&D } & \text { decontamination and decommissioning } \\ \text { DCGL } & \text { derived concentration guideline level } \\ \text { DOE } & \text { U.S. Department of Energy } \\ \text { ERDA } & \text { Energy Research and Development Administration } \\ \text { ETEC } & \text { Energy Technology Engineering Center } \\ \text { FSS } & \text { final status survey } \\ \text { GPS } & \text { global positioning system } \\ \text { ha } & \text { hectare } \\ \text { IEAV } & \text { Independent Environmental Assessment and Verification } \\ & \text { Program } \\ \text { ITP } & \text { Intercomparison Testing Program } \\ \text { km } & \text { kilometer } \\ \text { MAPEP } & \text { Mixed Analyte Performance Evaluation Program } \\ \text { MARSSIM } & \text { Multi-Agency Radiation Survey and Site Investigation Manual } \\ \text { MDC } & \text { minimum detectable concentration } \\ \text { MeV } & \text { million electron volts } \\ \text { m } & \text { meters } \\ \text { m } & \text { square meter } \\ \text { NaI } & \text { sodium iodide } \\ \text { NIST } & \text { National Institute of Standards and Technology } \\ \text { NRC } & \text { U.S. Nuclear Regulatory Commission } \\ \text { NRIP } & \text { NIST Radiochemistry Intercomparison Program } \\ \text { ORISE } & \text { Oak Ridge Institute for Science and Education } \\ \text { pCi/g } & \text { picocuries per gram } \\ \text { RSS } & \text { ranked set sampling } \\ \text { SOR } & \text { sum-of-ratios } \\ \text { SNAP } & \text { System for Nuclear Auxiliary Power } \\ \text { SSFL } & \text { Santa Susana Field Laboratory } \\ \text { TAP } & \text { total absorption peak } \\ & \end{array}$




\section{VERIFICATION SURVEY OF THE BUILDING 4059 SITE (PHASE B); POST HISTORICAL SITE ASSESSMENT SITES, BLOCK 1; and RADIOACTIVE MATERIALS HANDLING FACILITY HOLDUP POND (SITE 4614) SANTA SUSANA FIELD LABORATORY THE BOEING COMPANY VENTURA COUNTY, CALIFORNIA}

\section{INTRODUCTION AND SITE HISTORY}

The Boeing Company, formerly Rockwell International Rocketdyne Division, operates the Santa Susana Field Laboratory (SSFL). The Energy Technology Engineering Center (ETEC) is that portion of the SSFL, operated for the U.S. Department of Energy (DOE), which performed testing of equipment, materials, and components for nuclear and energy related programs. Contract work for the Atomic Energy Commission (AEC) and the Energy Research and Development Administration (ERDA), predecessor agencies to the DOE, began in the early 1950's. Specific programs conducted for AEC/ERDA/DOE involved engineering, developing, testing, and manufacturing operations for nuclear reactor systems and components. Other SSFL activities have also been conducted for the National Aeronautics and Space Administration, the U.S. Department of Defense, and other government related or affiliated organizations and agencies. Some activities have been licensed by the U.S. Nuclear Regulatory Commission (NRC) and by the State of California Radiologic Health Branch of the Department of Public Health.

Numerous buildings and land areas became radiologically contaminated as a result of the various operations which included ten reactors, seven criticality test facilities, fuel fabrication, reactor and fuel disassembly, laboratory work, and on-site storage of nuclear material. Potential radioactive contaminants identified at the site are uranium (in natural and enriched isotopic abundances), plutonium, Am-241, fission products (primarily Cs-137 and Sr-90), and activation products (tritium [H-3], Co-60, Eu-152, Eu-154, and Ni-63).

Decontamination and decommissioning (D\&D) of the radiologically contaminated facilities began in the late 1960's and continues today, as the remaining DOE program operations at ETEC were terminated effective September 30, 1995. As part of this D\&D program, Rocketdyne and Boeing have performed decommissioning and final status surveys (FSS) of a number of facilities that supported the various nuclear-related ETEC operations during the latter part of the 1950's and 
continuing through to the present. Environmental management of DOE contaminated properties continues under the ETEC Closure contract. Surveys to demonstrate compliance with both the DOE and California Department of Public Health cleanup standards have recently been completed for the following:

- $\quad$ Phase B of the Building 4059 decommissioning project;

- Area IV (Block 1) which includes the footprints of former buildings 4023, 4028, 4030, 4363, and 4583;

- $\quad$ Radioactive Materials Handling Holdup Pond (Site 4614).

Building 4059 was constructed during 1962 and 1963. The facility housed a research and development program known as the Systems for Nuclear Auxiliary Power (SNAP). This program was established to develop and test power systems for use as subsidiary nuclear power units in specialized applications. Atomic International developed the SNAP 8 reactor, under contract to the AEC, for use in this program. Reactor operation began in 1963 and the last test was conducted in 1969 at which time the reactor was shut down. Since reactor shut down, the facility has undergone various stages of the decommissioning process, culminating in the demolition of both the above- and below-grade structures. Surveys of the footprint were conducted in two phases: Phase A included the below-grade excavation and Phase B included the final, backfilled site and surrounding land. Site 4059 is located at the northwestern edge of Area IV.

Site 4023 contains the footprint of the Liquid Metals Component Test Building. The operations performed within the former building began in the 1960s and 1970s. The building was used for study of radioactive contamination transport using a sodium loop and chemistry labs, and had a waste hold-up tank with associated drains and pipes. Site 4023 is centrally located within Area IV.

Site 4028 is in the northwestern sector of Area IV and formerly housed the Shield Test Irradiation Reactor Facility, Shield Test Reactor, and the Liquid Metal Fast Breeder Reactor Fuel Safety Building. Operations consisted of tests on space reactor shields and behavior of molten uranium oxide. All activities ceased at this facility in 1984. 
Site 4030 is located towards the east-central side of Area IV. A counting room and a Van de Graaf accelerator were housed within the former building. Radiological operations in the facility had ended by 1972 .

The Mechanical Component Development and Counting and Research and Development Buildings were located at Site 4363 and supported the Sodium Reactor Experiment. Site 4363 is located in the southwest edge of Area IV.

Site 4583 encompasses the former Old Storage and Conservation Yards which are located in the northeastern sector of Area IV and were used for equipment storage. Use of the area to support nuclear-related work ended around 1977.

Site 4614 is where a hold-up pond was located that was constructed to contain surface runoff from the Radioactive Materials Disposal Facility and the Radioactive Materials Handling Facility.

All of the above sites have had any associated structures decontaminated and then demolished at various times. These decommissioning activities began during the 1980s, with most areas completed during the latter part of the 1990s. Boeing or a Boeing contractor have conducted the FSS of these Area IV land areas in accordance with guidance provided in the Multi-Agency Radiation Survey and Site Investigation Manual (NRC 2000). The results of these recent site surveys have been documented in various reports (Boeing 2006, Cabrera 2007a and b).

DOE is responsible for oversight of remedial actions that are conducted at the SSFL. It is the policy of DOE to perform independent (third party) verification of remedial action activities. The purpose of these independent verification activities is to confirm that remedial actions have been effective in meeting the established site-specific guidelines and that the documentation accurately and adequately describes the radiological conditions at the site. Oak Ridge Institute for Science and Education (ORISE) was designated as the organization responsible for this task at SSFL, and has been requested to verify the current radiological status of sites 4023, 4028, 4030, 4059 (Phase B), 4363, 4583, and 4614. ORISE previously verified Phase A of site 4059 (ORISE 2005). 


\section{SITE DESCRIPTION}

The SSFL is located in the Simi Hills of southeastern Ventura County, California, approximately 47 kilometers (km [29 miles]) northwest of downtown Los Angeles (Figure A-1). The site is comprised of approximately 1,090 hectares (ha [2,700 acres]) and is divided into four administrative areas (Areas I through IV) and a Buffer Zone. DOE operations were conducted in Boeing-owned facilities located within the 117 ha Area IV (Figure A-2). The ETEC portion of Area IV consists of government-owned buildings that occupy 36 ha. The locations of the seven areas verified are shown in Figure A-3.

\section{OBJECTIVE}

The objective of the verification survey was to confirm that the final radiological conditions were accurately and adequately described in the FSS documentation, relative to the established release criteria. This objective was achieved via multiple verification components which included document reviews and independent measurements and sampling. Specifically, documentation of the planning, implementation, and results of the FSS are evaluated; a comparison is performed of the mean residual radionuclide concentrations; site areas are evaluated relative to appropriate FSS classification; and areas are assessed for residual, undocumented contamination.

\section{DOCUMENT REVIEW}

ORISE reviewed the FSS procedures for the Building 4059 site and the FSS reports for all the sites (Boeing 2004 and 2006, Cabrera 2007a and b). Information was evaluated to assure that FSS procedures were appropriate for the radionuclides of concern and that residual activity levels satisfied the established radiological release criteria (ORISE 2007).

\section{PROCEDURES}

ORISE personnel visited the SSFL site from February 19 through 21, 2008 to perform visual inspections and independent measurements and sampling. The verification activities were conducted in accordance with a site-specific verification survey plan, the IEAV Survey Procedures and Quality Program Manuals (ORISE 2008a and b and ORAU 2007). 
The collective site areas verified consisted of twelve survey units totaling approximately $35,000 \mathrm{~m}^{2}$. Each survey unit was classified in accordance with MARSSIM, based on contamination potential. A description of each classification is as follows:

Class 1: $\quad$ Land areas that have a significant potential for radioactive contamination (based on site operating history) or known contamination (based on previous radiological surveys) that exceeds the expected DCGL $L_{\mathrm{W}}$.

Class 2: $\quad$ Areas that have, or had prior to remediation, a potential for radioactive contamination or known contamination, but are not expected to exceed the DCGL $\mathrm{W}_{\mathrm{W}}$.

Class 3: $\quad$ Any impacted areas that are not expected to contain residual contamination, or are expected to contain levels of residual contamination at a small fraction of the DCGL $_{W}$.

Survey unit information is summarized in the following table.

\begin{tabular}{|c|c|c|}
\hline \multicolumn{3}{|c|}{ TABLE 1: } \\
\hline \multicolumn{2}{|c|}{ AREA IV SITES SURVEY UNIT SUMMARY } \\
\hline Survey Unit ID & Site & Classification \\
\hline SU 3 & 4059 & 3 \\
\hline SU 10 & 4023 & 2 \\
\hline SU 11 & 4023 & 3 \\
\hline SU 12 & 4363 & 2 \\
\hline SU 13 & 4363 & 3 \\
\hline SU 14 & 4028 & 2 \\
\hline SU 15 & 4028 & 2 \\
\hline SU 16 & 4030 & 2 \\
\hline SU 17 & 4030 & 3 \\
\hline SU 18 & 4583 & 2 \\
\hline SU 19 & 4614 & 1 \\
\hline SU 20 & 4614 & 1 \\
\hline
\end{tabular}




\section{REFERENCE SYSTEM}

Global positioning system (GPS) coordinates were used for referencing measurement and sampling locations. The specific reference system used was WGS 84 UTM Zone 11.

\section{SURFACE SCANS}

Medium density gamma radiation surface scans were conducted over all survey units. Surface scans were performed using $\mathrm{NaI}$ scintillation detectors coupled to ratemeter-scalers with audible indicators. Detectors were also coupled to GPS systems that enabled real-time gamma count rate and position data capture. Field personnel relied on the audio output to identify and mark for further investigations any locations of elevated direct gamma radiation that might suggest the presence of residual contamination.

\section{SOIL SAMPLING}

A ranked set sampling (RSS) approach was used to design the verification soil sampling plan (EPA 2002). RSS provides a methodology to estimate the mean concentration of a population but does not require the assumption of a normal distribution. The process combines random sampling with the use of professional judgment to select sampling locations. The professional judgment relied upon the ability to assess the relative magnitude of gamma radiation levels between randomly selected locations. In this case, the gamma count rate data collected at randomly selected locations provided the measurable field screening method that correlates with the relative concentrations of the gamma-emitting contaminants of concern. The count rate data obtained were then used to select a specific sampling location.

The following example explains the process:

- The Visual Sampling Plan v.4.6, or higher, RSS module is used to determine the necessary number of soil samples to estimate the mean. The number of measurements is based on the expected standard deviation and desired confidence level of the estimated mean. 
- For this example, assume that the systematic planning process resulted in $n=12$ soil samples to estimate the mean.

- The next step is to use a replication process on a larger random population from which the locations for the 12 soil samples will be selected.

- The replication process is referred to as a cycle, designated as $r$.

- Each cycle $(r)$ consists of multiple sets; sets are designated as $m$.

- Each set $(m)$ is comprised of a set size, or field assessment locations. The data from each set are ultimately the values that are ranked, for this example the ranked values are direct gamma counts. The set size should consist of 2 to 5 field assessment locations. For this project a set size consisted of 3 locations, the gamma count data collected from the 3 locations associated with each set were ranked as being either the low, medium, or high gamma count locations. The three ranking categories establish the set size.

- The total number of repetitive cycles (r) is a function of $n(12)$ and $m$ (3) - or simply defined as $n=m \times r . \quad r$ for this example would therefore be $4(r=12 / 3)$.

- The number of field assessment locations per cycle, is a function of the set size and is simply $m^{2}$. The total number of field assessment locations is then defined as $m^{2} \times r$ or in this example $3^{2} \times 4=36$.

- The 36 locations are then both randomly grouped into cycle/sets and distributed in the survey area. The nomenclature for identifying a specific assessment location is cycle \#-set\#-arbitrary sequence \# (1, 2, or 3$)$. The first location in cycle 1 of set 1 would be designated as 1-1-1. Mapping is color coded (based on cycle ID) using geometric shapes (based on set ID) to visually show the population of assessment locations.

- Specific measurement locations are generated via either a pseudo- or quasi-random approach.

Figure 1 is an example of an RSS measurement/sampling plan. 


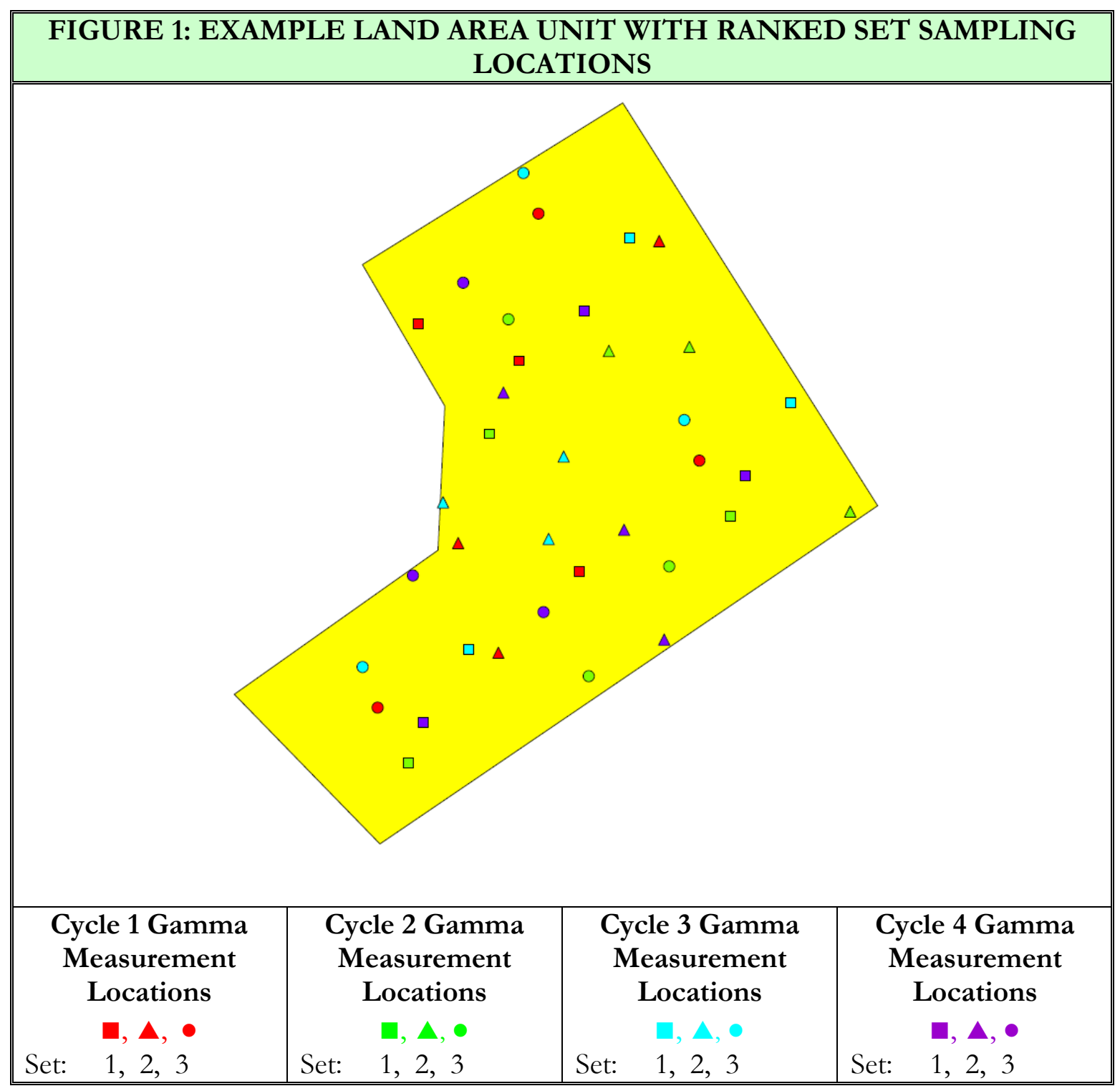

Gamma measurements are collected at each of the 36 assessment locations and the data within a given cycle-set are then ranked as exhibiting either the lowest, medium, or highest gamma count. Soil samples are collected in accordance with the following process within each of the 4 cycles: Set 1, lowest gamma radiation location; Set 2 medium location; Set 3 highest location. Table B-1 provides the RSS method showing field assessment data and the location selected for soil sampling.

The Boeing and Cabrera survey unit FSS data were used to determine the number of random verification samples necessary to verify the mean concentrations. Specifically, the inputs used were 
the respective modified DCGLs for the primary surrogate radionuclides — Cs-137 and Eu-152 - the maximum sum-of-ratios value between Eu-152 (from only area 4059) and Cs-137 (from all areas), and the observed maximum variability. There were two area sample planning groups as follows: areas 4059 and 4583 served as sampling Group 1 and areas 4023, 4028, 4030, 4363 and 4614 were included together as Group 2. The decision to pool the verification data for the survey units was based on the evaluation of the mean concentration and standard deviation of the contaminant of concern for each survey unit, comparison of the mean and median for skewness, then examining the maximum individual sample concentrations from each survey unit for outliers via determination of the interquartile range. This evaluation determined that the population was essentially normally distributed and that there was only one sample that would be considered a statistical outlier of the grouped population.

Twelve random surface ( 0 to $15 \mathrm{~cm}$ ) samples were collected from Group 1 and nine samples were collected from Group 2. The specific random coordinate sampled was from a preliminary random coordinate pool of 36 locations in Group 1 and 27 locations in Group 2. A one-minute static gamma count rate measurement was performed at each location. Twenty-one sets of three locations each were then ranked as exhibiting either the lowest, middle, or highest gamma count rate. One sample was then collected in a cyclic process from either the lowest, middle, or highest random coordinate from each of these twenty-one sets. The software Visual Sample Plan v.4.6 was used to generate the random locations. Figures A-4 through A-7 show the random ranking locations and the soil sample locations.

\section{SAMPLE ANALYSIS AND DATA INTERPRETATION}

Samples and data were returned to the ORISE laboratory in Oak Ridge, Tennessee for analysis and interpretation. Sample analyses were performed in accordance with the IEAV Laboratory Procedures Manual (ORISE 2008c). Soil samples were analyzed by gamma spectroscopy for Cs-137 and Eu-152. The spectra were also reviewed for other identifiable photopeaks. Soil sample results were reported in units of picocuries per gram $(\mathrm{pCi} / \mathrm{g})$.

The data generated were compared with the approved release criteria established for Area IV at the SSFL, with the modified Cs-137 and Eu-152 DCGLs serving as the primary criteria (DOE 1993 and 
1996 and SCDHS 1996). The modified DCGLs were 4.7 and $2.8 \mathrm{pCi} / \mathrm{g}$ for Cs-137 and Eu-152, respectively. The sum-of-ratios were also calculated in accordance with the equation:

$$
\frac{\text { Conc. }_{C s-137}}{D C G L_{C s-137}}+\frac{\text { Conc }_{E u-152}}{D C G L_{E u-152}}<1
$$

\section{FINDINGS AND RESULTS}

The results for each verification component are discussed below.

\section{DOCUMENT REVIEW}

ORISE's review of Boeing's project documentation indicated that most procedures and methods implemented for the FSS were appropriate and that the resultant data were acceptable. The results of the reviews and comments identified were provided to the DOE (ORISE 2006 and 2007). Responses that adequately addressed identified comments have been provided (Cabrera 2008).

\section{SURFACE SCANS}

Gamma radiation surface scans did not identify any locations of elevated direct radiation. Area gamma scan count rates generally ranged from 4,500 to 7,800 counts per minute with the variability in the ambient gamma radiation levels consistent with the localized area topography and geology. Gamma scan results are illustrated in Figures A-8 through A-14 for each area. Data are provided as the gross, observed count rates. Figure A-15 provides a frequency histogram of the combined gamma count rate data population.

\section{RADIONUClide CONCENTRATIONS IN SOIL SAMPLES}

The summary data for the two combined survey groupings are presented in Table 2 below. The data for the radionuclide concentrations in individual samples and the sum-of-ratios are provided in Table B-2. The gamma count rate data used for selecting the appropriate sample locations are shown in Table B-1. 


\begin{tabular}{|c|c|c||}
\hline \multicolumn{3}{|c|}{ TABLE 2: } \\
RADIONUCLIDE CONCENTRATIONS IN SOIL SAMPLES \\
SUMMARY RESULTS
\end{tabular}

\section{COMPARISON OF RESULTS WITH RELEASE CRITERIA}

Radionuclide concentrations in soil samples were directly compared with the modified Cs-137 and Eu-152 release limits of $4.7 \mathrm{pCi} / \mathrm{g}$ for Cs-137 and $2.8 \mathrm{pCi} / \mathrm{g}$ for Eu-152. All individual sample results and the SORs were less than the release criteria. Furthermore, the verification mean concentrations across the survey areas, provided above in Table 2, were compared with the mean concentrations that ORISE calculated from the site's FSS results for each survey unit. The calculated site mean concentrations of $0.02 \mathrm{pCi} / \mathrm{g}$ for Cs-137 and $0.08 \mathrm{pCi} / \mathrm{g}$ for Eu-152 and the verification mean concentrations are comparable. These data validated the site's FSS results. Additionally, the independent surveys validated area classifications.

\section{SUMMARY}

The Oak Ridge Institute for Science and Education performed verification activities for seven site areas at the Santa Susana Field Laboratory. These activities included the review and assessment of the final status survey reports and during the period February 19 through 21, 2008 independent measurements and sampling were performed. The verification results confirmed Boeing's conclusions regarding each area's classification, final radiological status, and that the release limits have been satisfied. 


\section{REFERENCES}

Boeing/Rocketdyne (Boeing). Building 4059 Final Status Survey Procedure. Ventura County, CA; September 10, 2004.

The Boeing Company (Boeing). Building 4059 Site Final Status Survey Report (Phase A and B). Canoga Park, CA; April 21, 2006.

Cabrera Services (Cabrera). Final Status Survey Report: Final Status Survey Post Historical Site Assessment Sites, Block 1. Las Vegas, NV; March 2007a.

Cabrera Services. Final Characterization and Final Status Survey Report: Radioactive Materials Handling Facility Holdup Pond (Site 4614). Las Vegas, NV; March 2007b.

Cabrera Services. Response to Comments on the Final Status Survey Reports (FSSRs) for the Post HSA Sites Area IV, Block 1 and the RMHF Holdup Pond (Site 4614). Las Vegas, NV; April 9, 2008.

Oak Ridge Associated Universities (ORAU). Quality Program Manual for the Independent Environmental Assessment and Verification Program. Oak Ridge, TN; November 1, 2007

Oak Ridge Institute for Science and Education (ORISE). Verification Survey of the Building 4059 Excavation, Santa Susana Field Laboratory, the Boeing Company, Ventura County, California. Oak Ridge, TN; March 1, 2005.

Oak Ridge Institute for Science and Education. Document Review_Building 4059 Site Final Status Survey Report (Phase A and B), Santa Susana Field Laboratory, the Boeing Company, Ventura County, California. Oak Ridge, TN; July 28, 2006.

Oak Ridge Institute for Science and Education. Document Reviews-Building 4059 Site Final Status Survey Report (Phase A and B); Final Status Survey Report: Final Status Survey Post Historical Site Assessment Sites, Block 1; and Final Characterization and Final Status Survey Report: Radioactive Materials Handling Facility Holdup Pond (Site 4614) Santa Susana Field Laboratory, The Boeing Company, Ventura County, California. Oak Ridge, TN; December 18, 2007.

Oak Ridge Institute for Science and Education. Final—Verification Survey Plan for the Building 4059 Site (Phase B); Post Historical Site Assessment Sites, Block 1; and Radioactive Materials Handling Facility Holdup Pond (Site 4614), Santa Susana Field Laboratory Ventura County, California. Oak Ridge, TN; February 15, 2008 a.

Oak Ridge Institute for Science and Education. Survey Procedures Manual for the Independent Environmental Assessment and Verification Program. Oak Ridge, TN; January 18, 2008b.

Oak Ridge Institute for Science and Education. Laboratory Procedures Manual for the Independent Environmental Assessment and Verification Program. Oak Ridge, TN; November 1, 2008c.

State of California, Department of Health Services (SCDHS). Authorized Sitewide Radiological Guidelines for Release of Unrestricted Use. August 9, 1996. 


\section{REFERENCES (CONTINUED)}

U.S. Department of Energy (DOE). Radiation Protection of the Public and the Environment. Washington, DC: DOE Order 5400.5; January 7, 1993.

U.S. Department of Energy. Memorandum from S. Robinson to R. Liddle, "Sitewide Limits for Release of Facilities Without Radiological Restrictions”. September 17, 1996.

U. S. Environmental Protection Agency (EPA). Guidance on Choosing a Sampling Design for Environmental Data Collection for Use in Developing a Quality Assurance Project Plan, EPA QA/G-5S. Washington, DC; December 2002.

U.S. Nuclear Regulatory Commission (NRC). Multi-Agency Radiation Survey and Site Investigation Manual (MARSSIM), NUREG-1575; Revision 1. Washington, DC; August 2000. 
APPENDIX A

FIGURES 


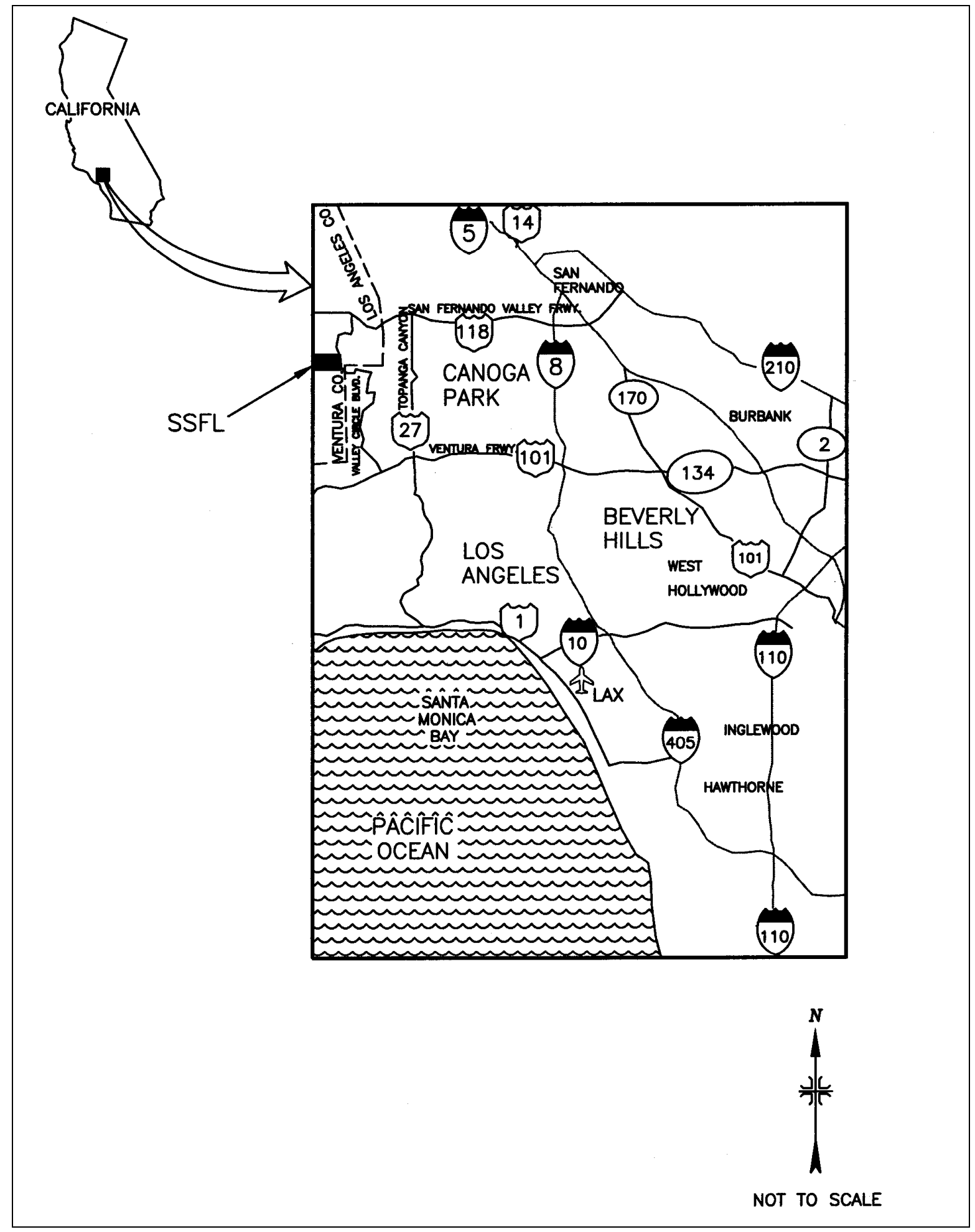

Figure A-1: Location of the Santa Susana Field Laboratory (SSFL) 


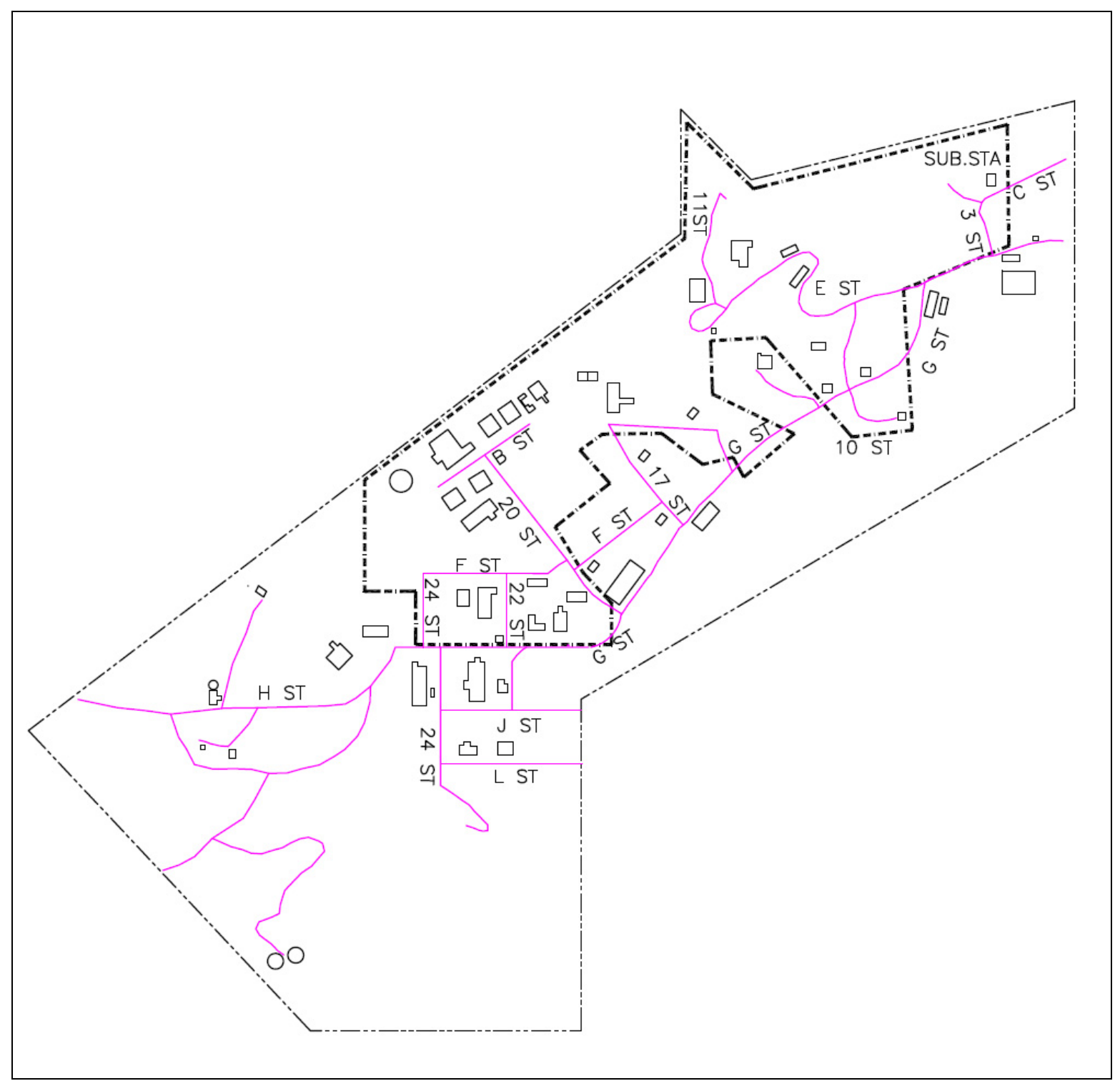

Figure A-2: Santa Susana Field Laboratory, Area IV_-Plot Plan 


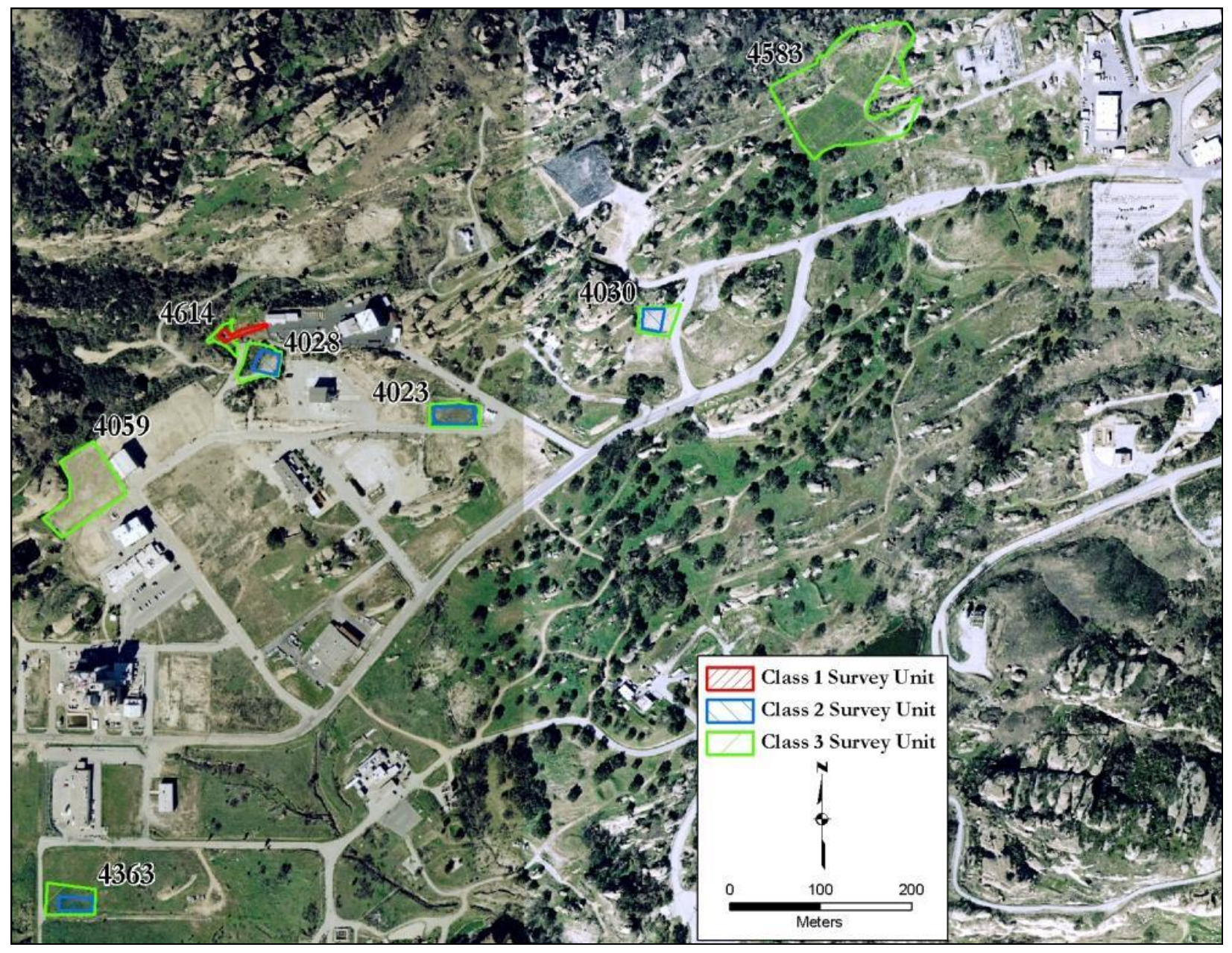

Figure A-3: Santa Susana Field Laboratory, Area IV-Survey Areas and Survey Unit Classifications 


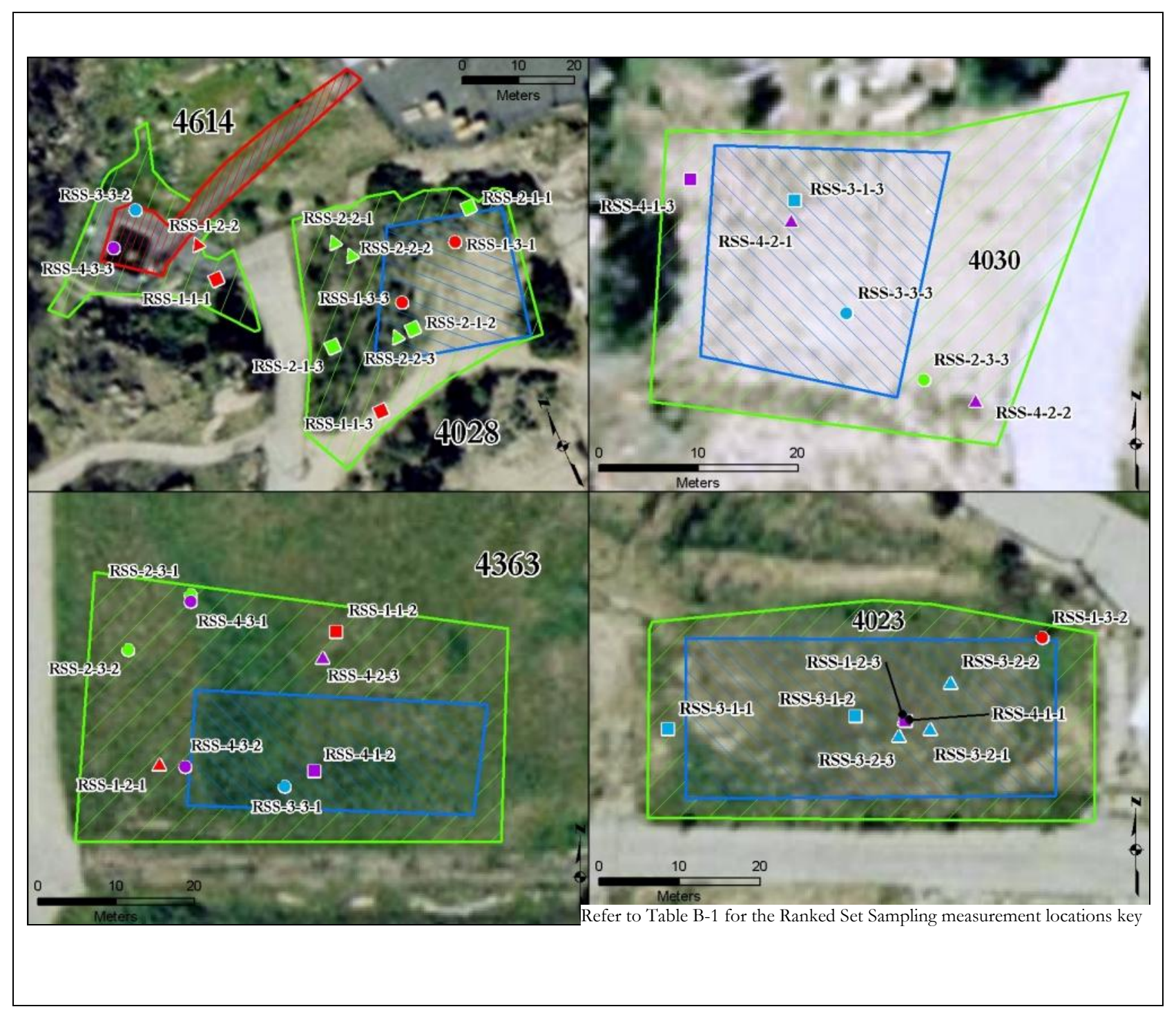

Figure A-4: Group 1 Verification Population, Survey Areas-Ranked Set Sampling Measurement Locations 


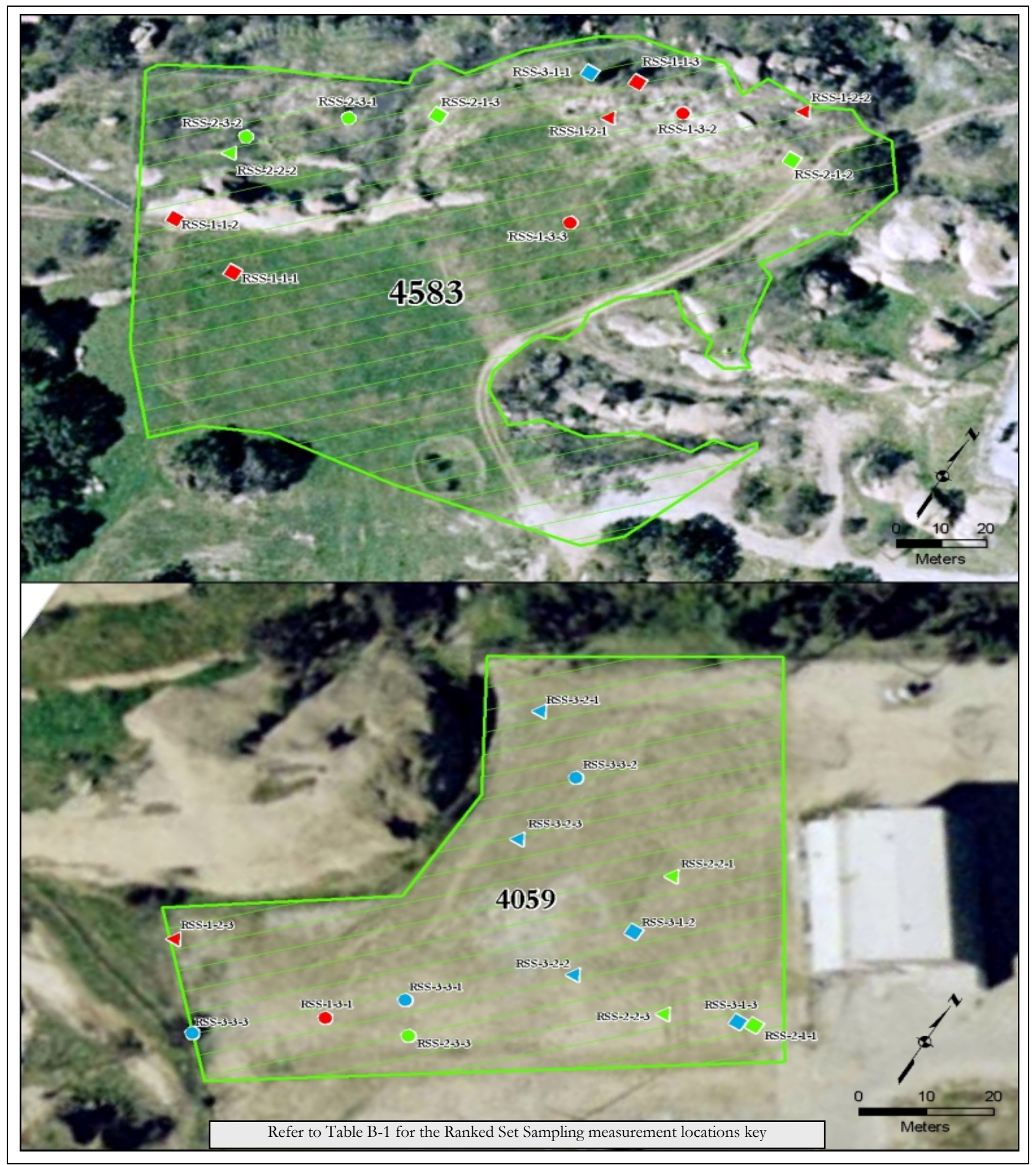

Figure A-5: Group 2 Verification Population, Survey Areas-Ranked Set Sampling Measurement Locations 


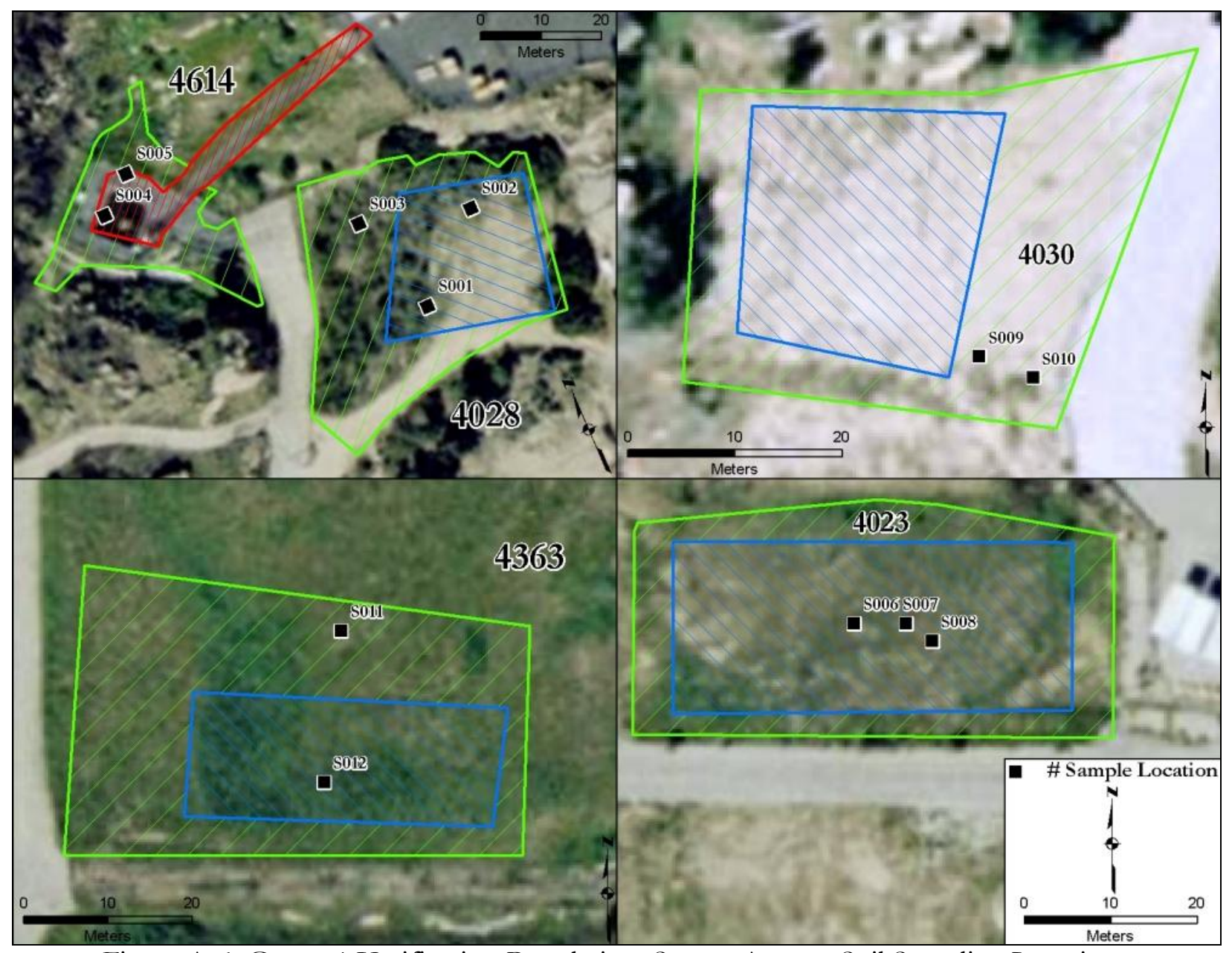

Figure A-6: Group 1 Verification Population, Survey Areas_-Soil Sampling Locations 


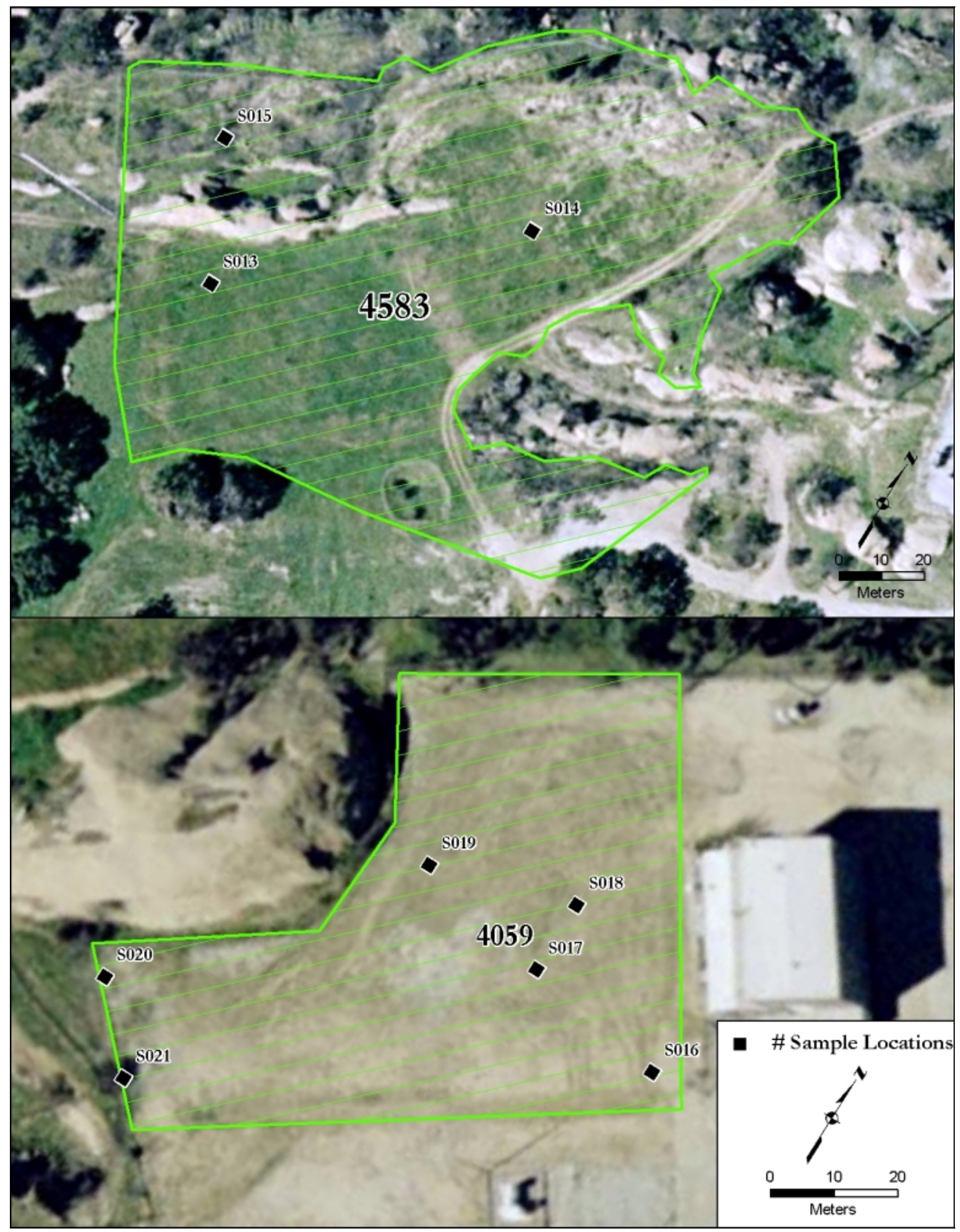

Figure A-7: Group 2 Verification Population, Survey Areas-Soil Sampling Locations 


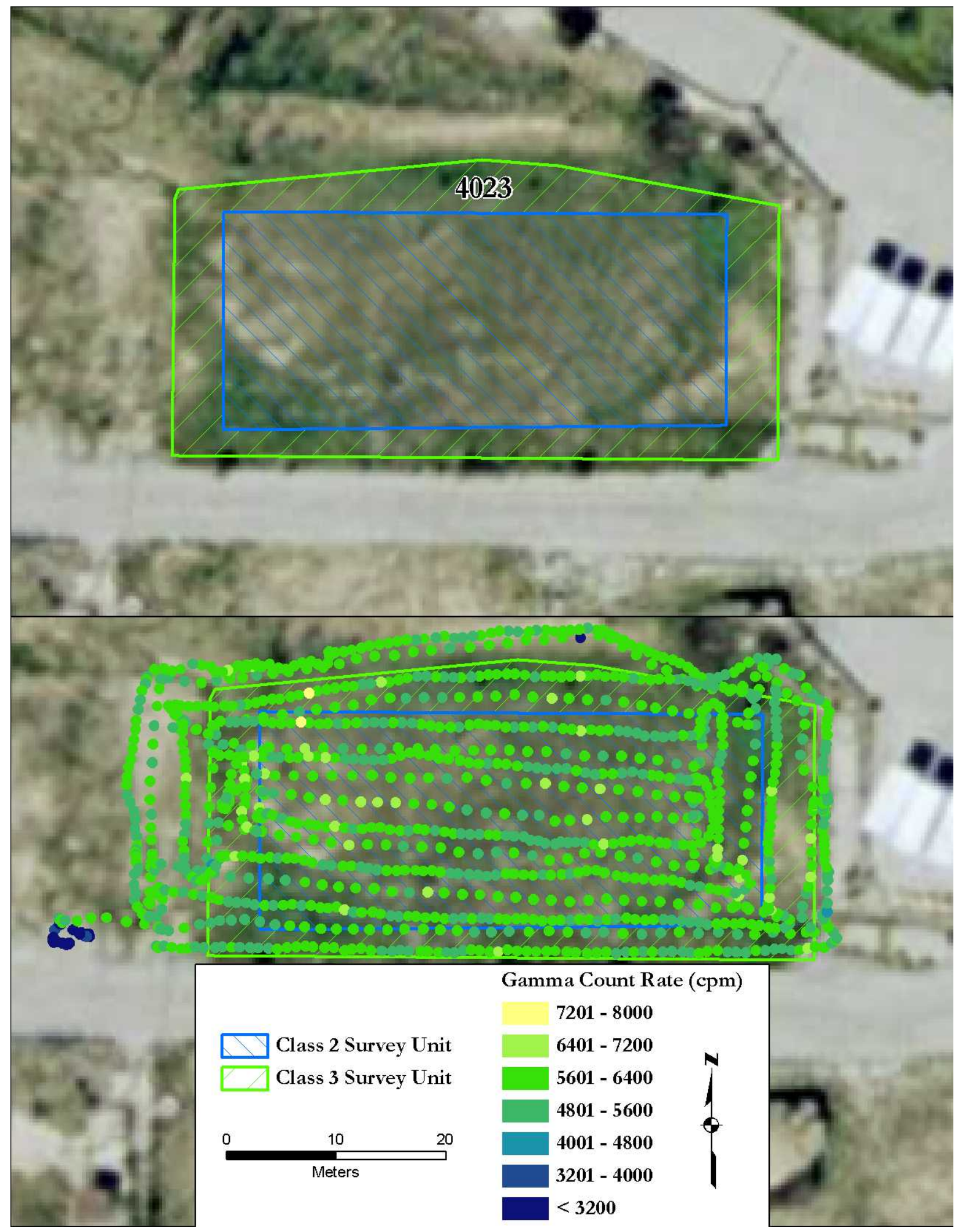

Figure A-8: Area 4023—Survey Area and Gamma Scans 


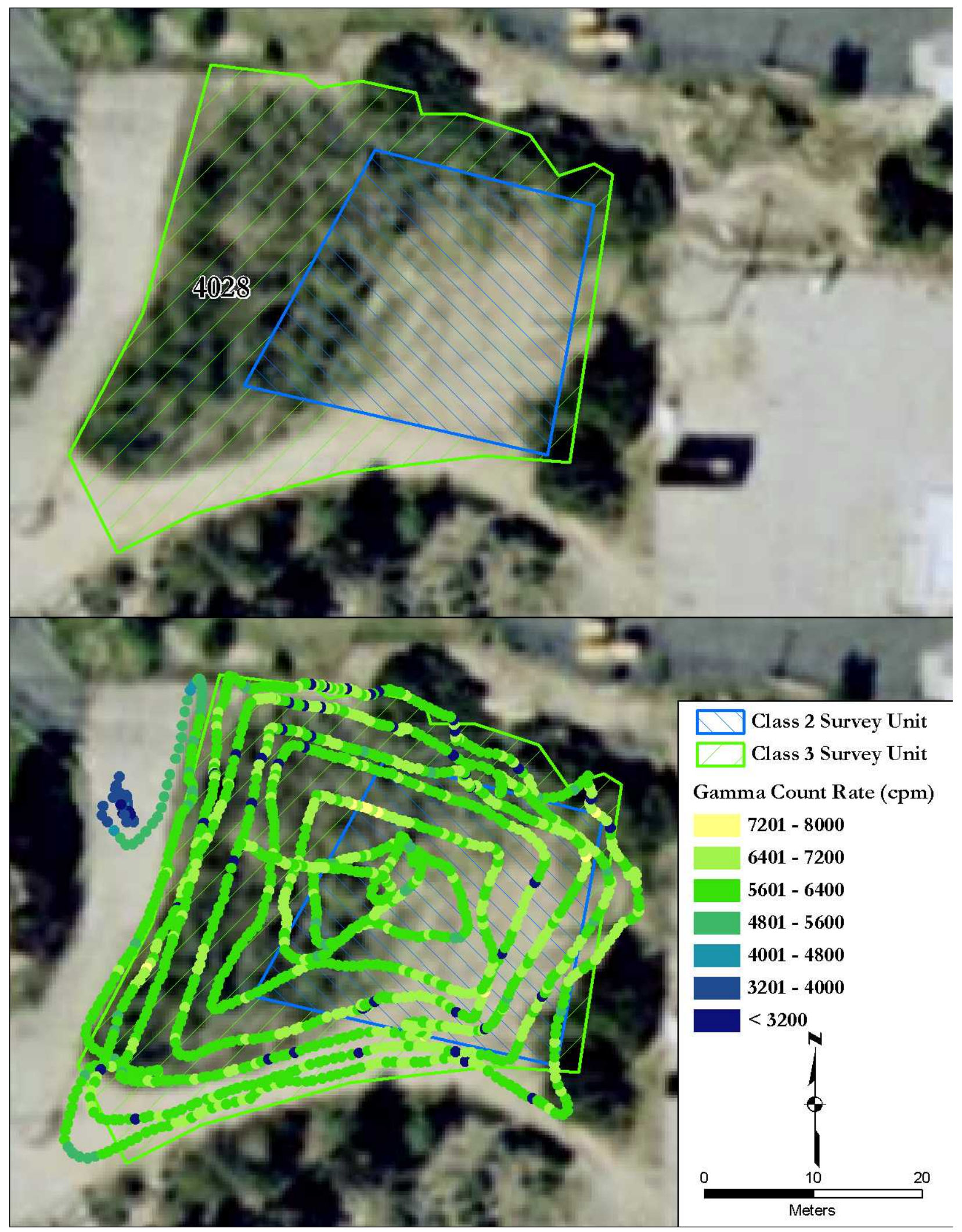

Figure A-9: Area 4028—Survey Area and Gamma Scans 


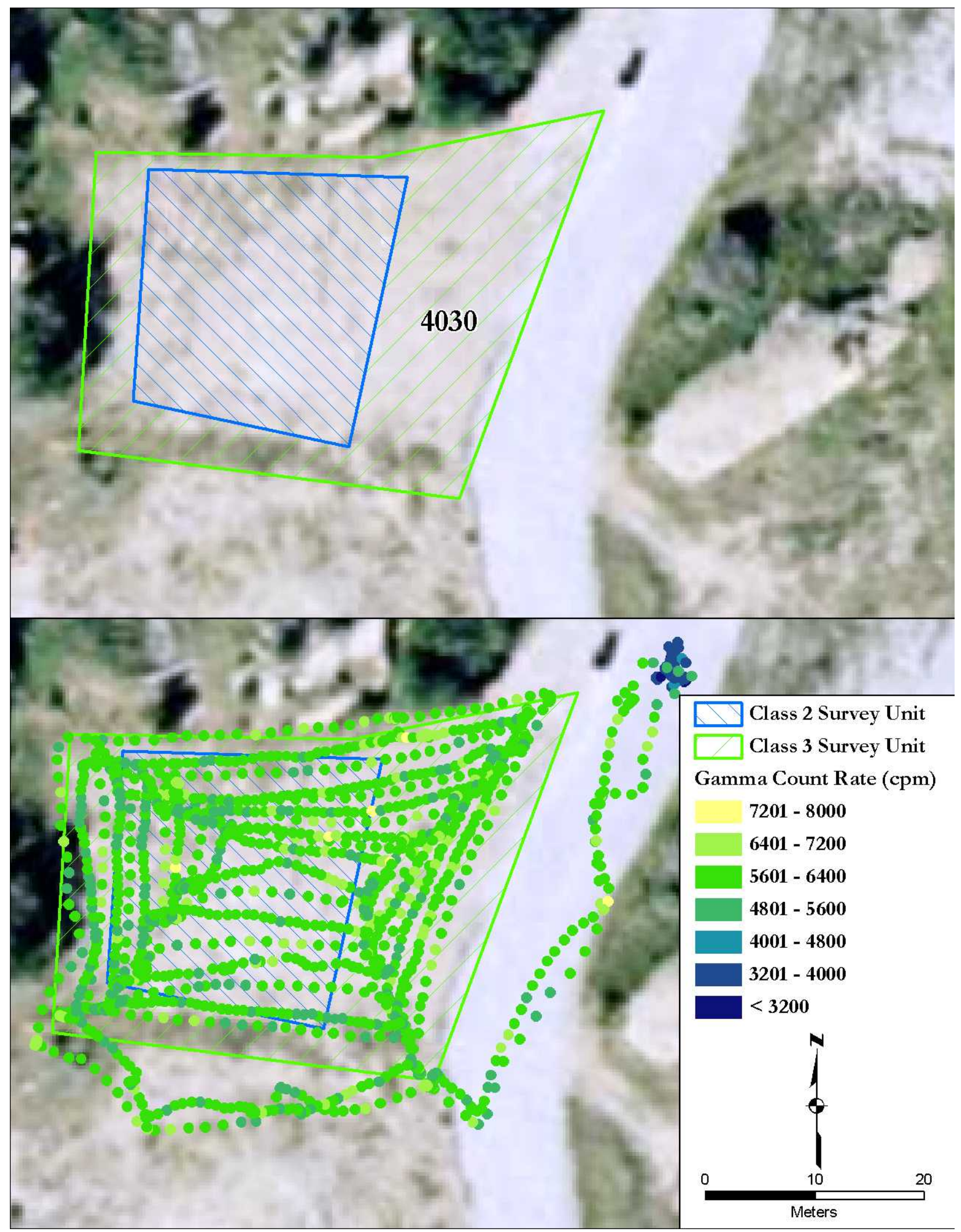

Figure A-10: Area 4030—Survey Area and Gamma Scans 


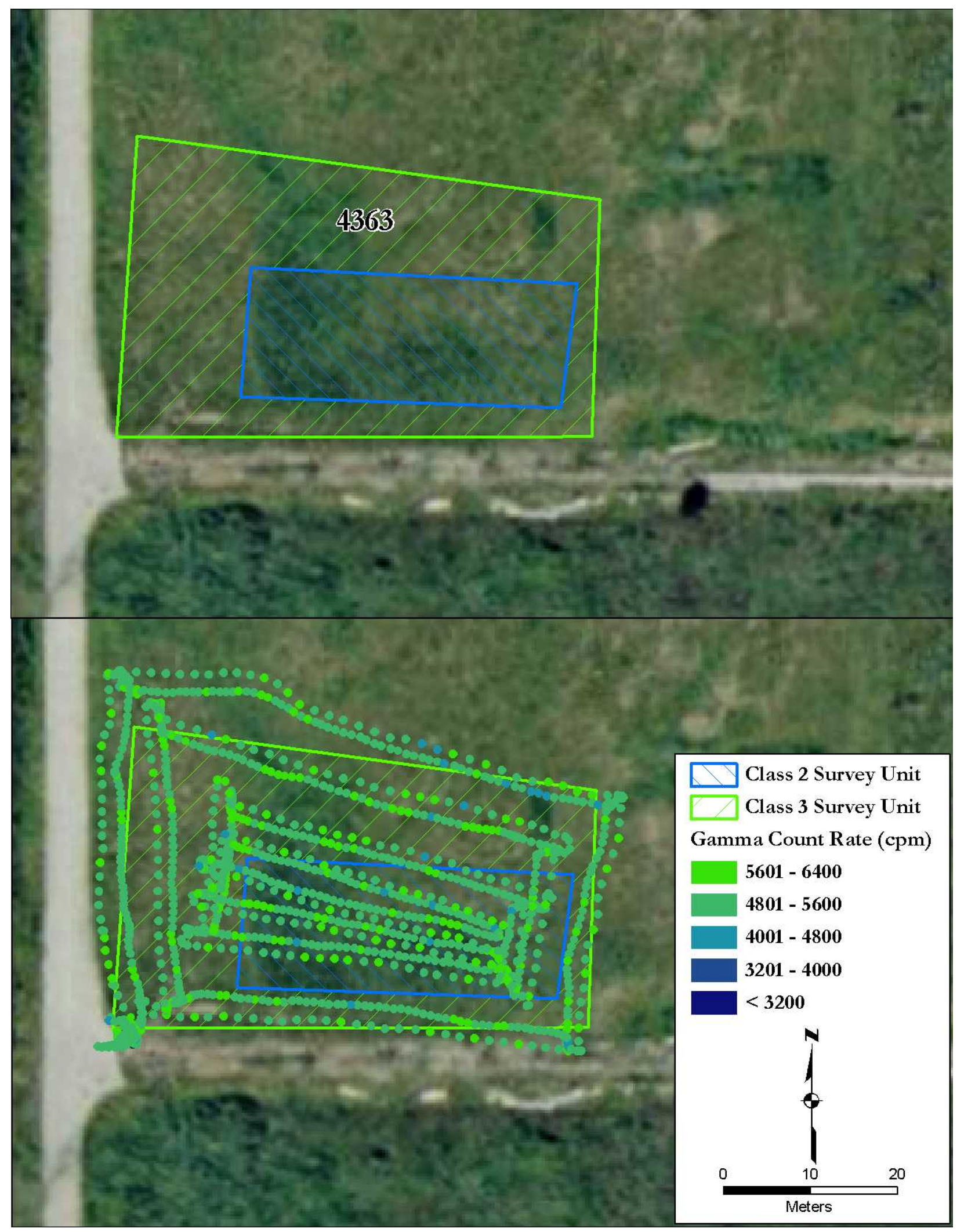

Figure A-11: Area 4363—Survey Area and Gamma Scans 


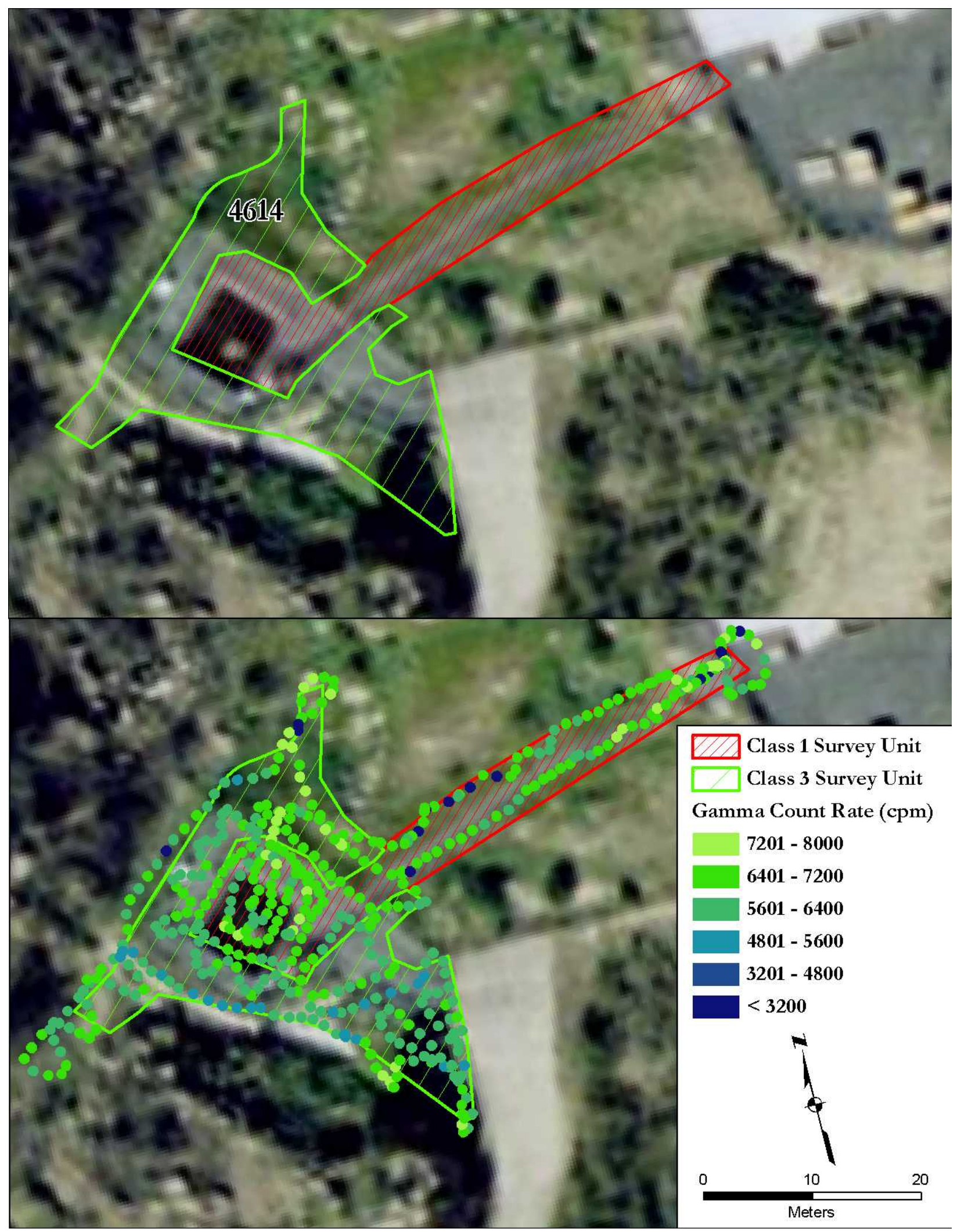

Figure A-12: Area 4614—Survey Area and Gamma Scans 


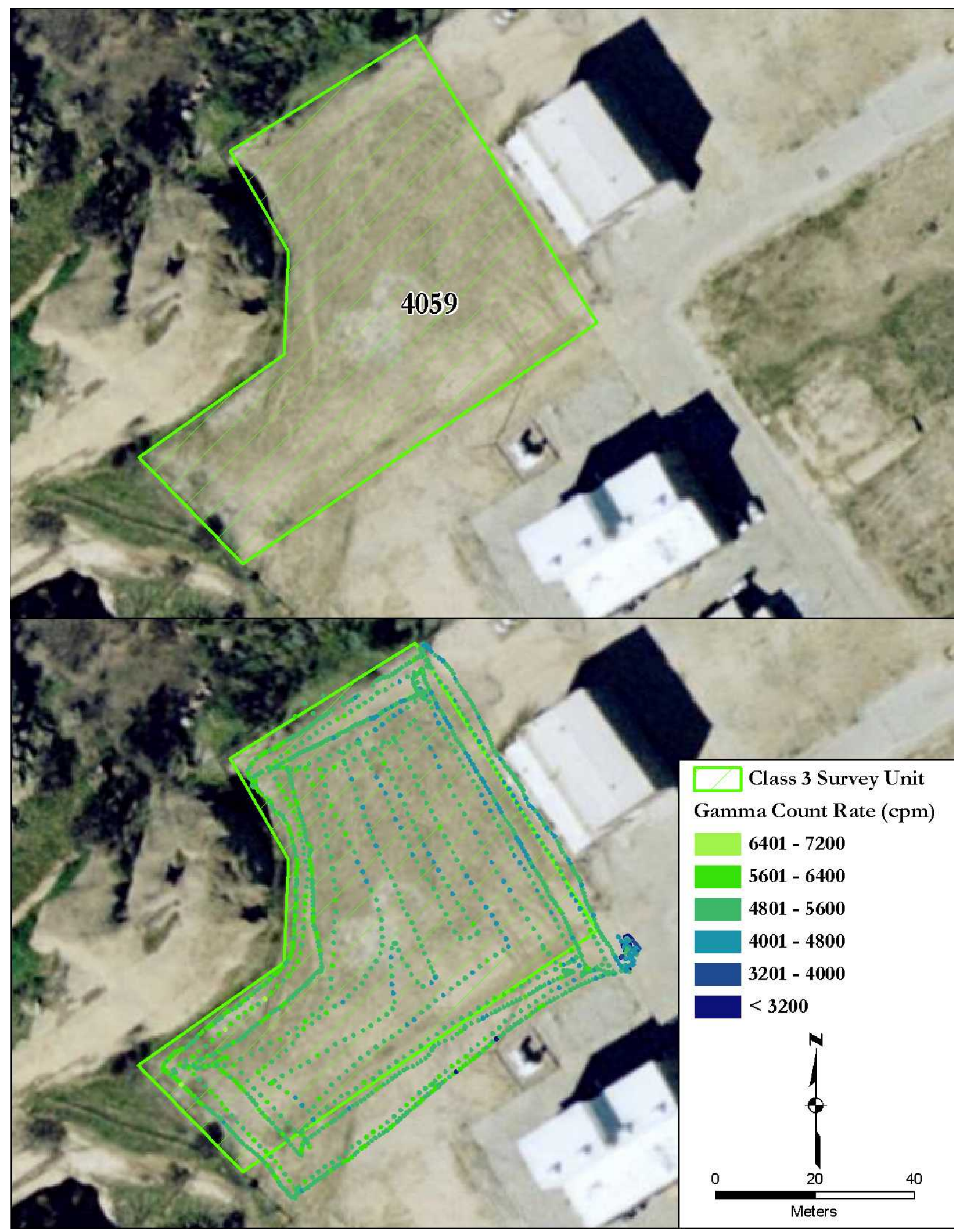

Figure A-13: Area 4059—Survey Area and Gamma Scans 


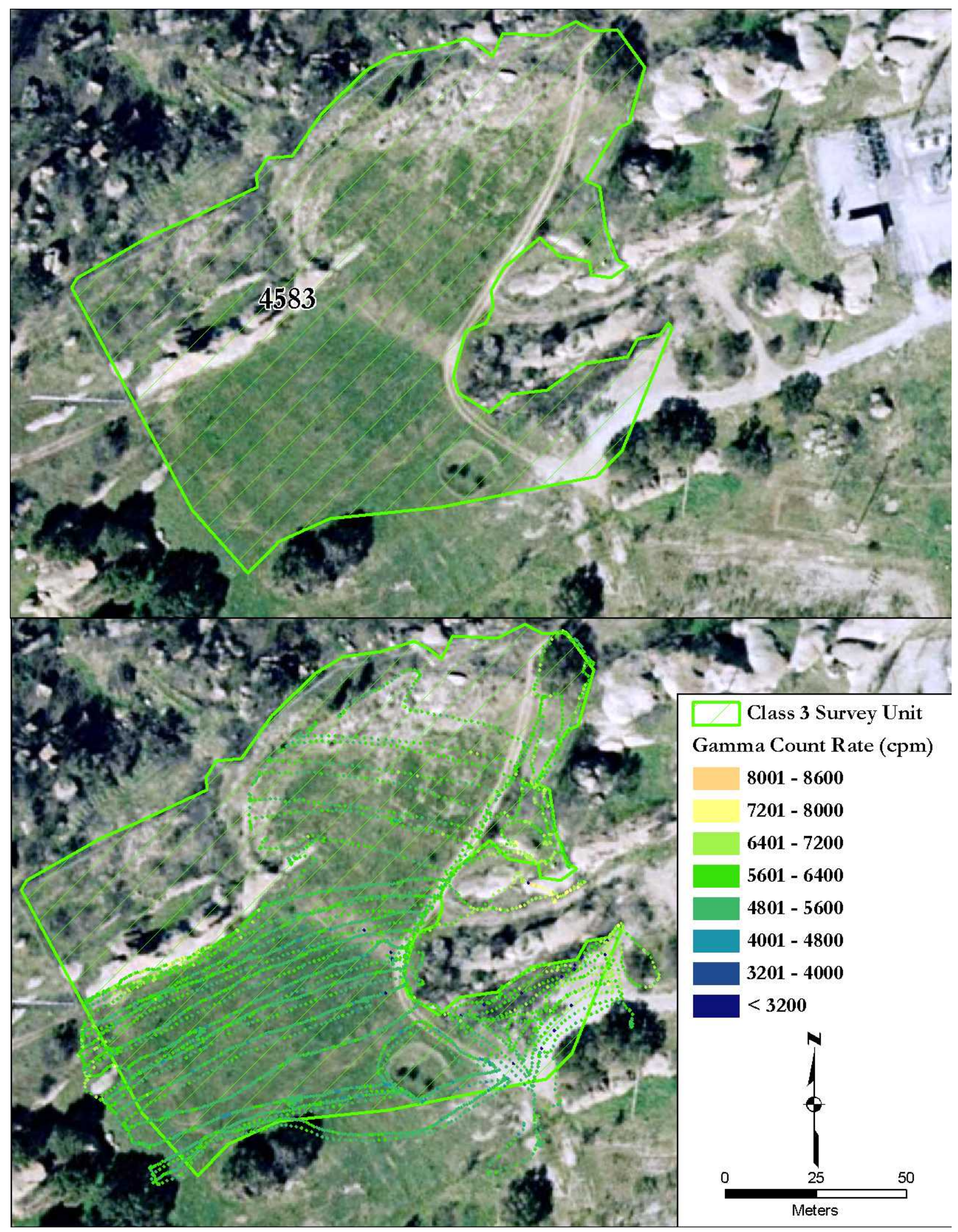

Figure A-14: Area 4583—Survey Area and Gamma Scans 


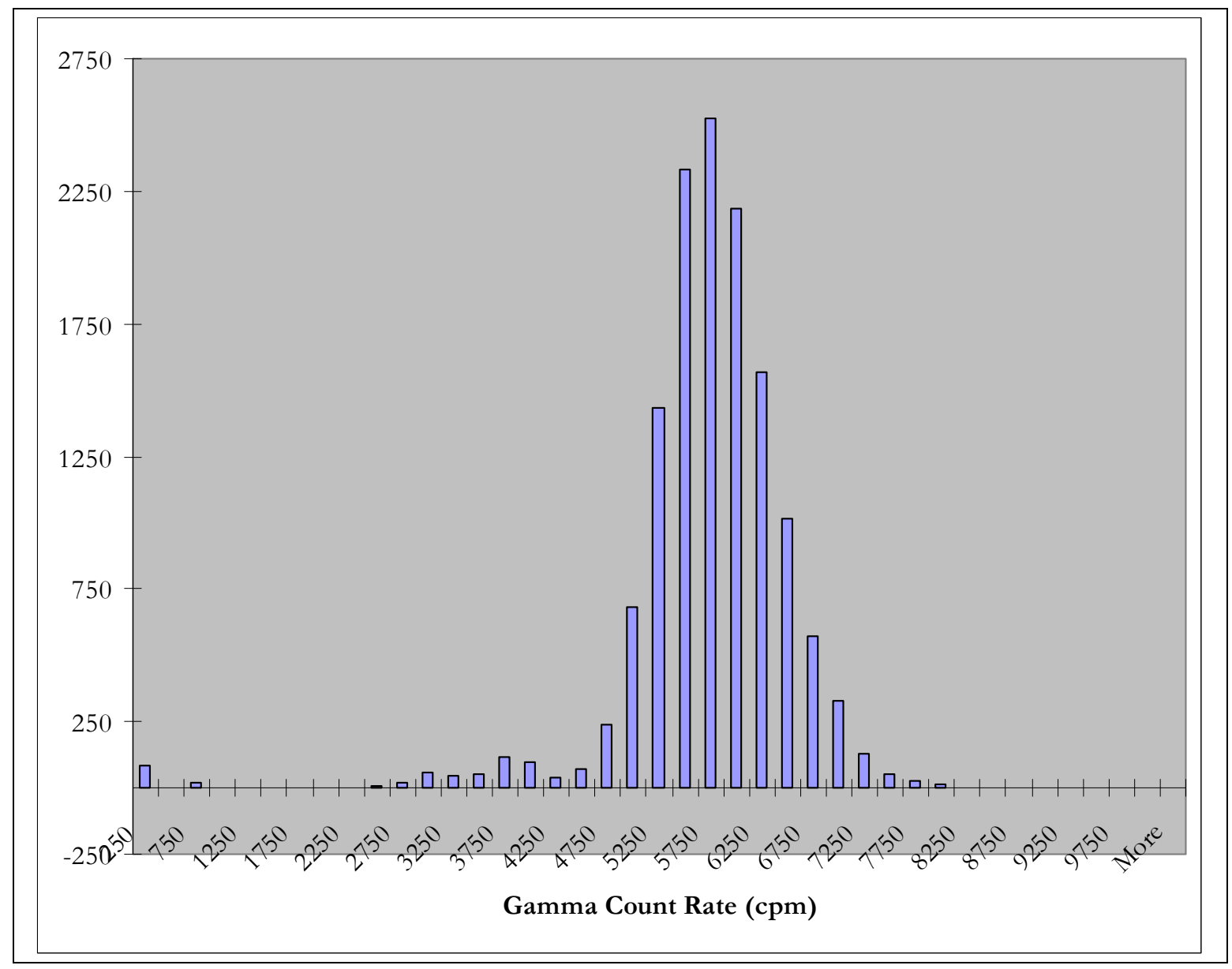

Figure A-15: Verification Gamma Scan Count Rate Histogram (Combined Data) 
APPENDIX B

TABLES 


\begin{tabular}{|c|c|c|c|}
\hline \multicolumn{4}{|c|}{$\begin{array}{c}\text { TABLE B-1: } \\
\text { RANKED SET SAMPLING GAMMA MEASUREMENTS } \\
\text { SANTA SUSANA FIELD LABORATORY } \\
\text { VENTURA COUNTY, CALIFORNIA }\end{array}$} \\
\hline \multirow{2}{*}{$\begin{array}{c}\text { Location } \\
\text { Northing, Easting/Area }\end{array}$} & Ranked Set Sampling & Gamma & \multirow{2}{*}{$\begin{array}{c}\text { Sample } \\
\text { Select }^{\mathrm{b}} / \mathrm{ID} \\
\text { L=Low } \\
\text { M=Medium } \\
\text { H=High }\end{array}$} \\
\hline & Cycle-Set-Map Code ${ }^{a}$ & cpm & \\
\hline \multicolumn{4}{|c|}{ Group 1} \\
\hline $3789365,342346 / 4028$ & $1-1-3=$ & 6129 & $\mathrm{~L}$ \\
\hline $3788798,342154 / 4363$ & $1-1-2$ 口 & 5389 & L/S011 \\
\hline $3789398,342329 / 4614$ & $1-1-1=$ & 6150 & $\mathrm{~L}$ \\
\hline $3788781,342132 / 4363$ & $1-2-1 \Delta$ & 5243 & $\mathrm{M}$ \\
\hline $3789323,342577 / 4023$ & $1-2-3 \Delta$ & 5567 & M/S007 \\
\hline $3789406,342328 / 4614$ & $1-2-2 \Delta$ & 5785 & $\mathrm{M}$ \\
\hline $3789333,342594 / 4023$ & $1-3-2 \bullet$ & 5577 & $\mathrm{H}$ \\
\hline $3789382,342357 / 4028$ & $1-3-3 \bullet$ & 6209 & $\mathrm{H}$ \\
\hline $3789388,342370 / 4028$ & $1-3-2 \bullet$ & 6416 & $\mathrm{H} / \mathrm{S} 002$ \\
\hline $3789379,342343 / 4028$ & $2-1-3$ & 6305 & $\mathrm{~L}$ \\
\hline $3789392,342375 / 4028$ & $2-1-1=$ & 6491 & $\mathrm{~L}$ \\
\hline $3789376,342357 / 4028$ & $2-1-2=$ & 6181 & $\mathrm{~L} / \mathrm{S} 001$ \\
\hline $3789393,342352 / 4028$ & $2-2-2 \Delta$ & 6281 & $\mathrm{M} / \mathrm{S} 003$ \\
\hline $3789396,342351 / 4028$ & $2-2-1 \Delta$ & 6423 & $\mathrm{M}$ \\
\hline $3789377,342354 / \mathbf{4 0 2 8}$ & $2-2-3 \Delta$ & 6233 & $\mathrm{M}$ \\
\hline $3789417,342803 / 4030$ & $2-3-3 \bullet$ & 5930 & H/S009 \\
\hline $3788796,342128 / 4363$ & $2-3-2 \bullet$ & 5378 & $\mathrm{H}$ \\
\hline $3788803,342136 / 4363$ & $2-3-1 \bullet$ & 5384 & $\mathrm{H}$ \\
\hline $3789321,342548 / 4023$ & $3-1-1$ & 6373 & $\mathrm{~L}$ \\
\hline $3789323,342571 / 4023$ & $3-1-2$ & 5701 & $\mathrm{~L} / \mathrm{S} 006$ \\
\hline $3789435,342790 / 4030$ & $3-1-3$ & 6221 & $\mathrm{~L}$ \\
\hline $3789320,342577 / 4023$ & $3-2-3 \triangle$ & 5627 & $\mathrm{M}$ \\
\hline $3789321,342580 / \mathbf{4 0 2 3}$ & $3-2-1 \Delta$ & 5761 & M/S008 \\
\hline $3789327,342583 / 4023$ & $3-2-2 \Delta$ & 5781 & $\mathrm{M}$ \\
\hline $3789416,342320 / 4614$ & $3-3-2$ & 6672 & $\mathrm{H} / \mathrm{S} 005$ \\
\hline $3788778,342148 / 4363$ & $3-3-1 \bullet$ & 5504 & $\mathrm{H}$ \\
\hline $3789423,342795 / 4030$ & $3-3-3 \circ$ & 6245 & $\mathrm{H}$ \\
\hline $3789437,342779 / 4030$ & $4-1-3 \square$ & 5836 & $\mathrm{~L}$ \\
\hline $3789322,342577 / 4023$ & $4-1-1 \square$ & 5691 & $\mathrm{~L}$ \\
\hline $3788780,342152 / 4363$ & $4-1-2 \square$ & 5325 & L/S012 \\
\hline $3789415,342808 / 4030$ & $4-2-1 \Delta$ & 5962 & $\mathrm{M}$ \\
\hline $3788795,342153 / 4363$ & $4-2-3 \Delta$ & 5345 & $\mathrm{M}$ \\
\hline $3789433,342789 / 4030$ & $4-2-2 \boldsymbol{\Delta}$ & 6007 & $\mathrm{M}$ \\
\hline $3788781,342135 / 4363$ & $4-3-2 \bullet$ & 5425 & $\mathrm{H}$ \\
\hline $3788802,342136 / 4363$ & $4-3-1 \bullet$ & 5299 & $\mathrm{H}$ \\
\hline
\end{tabular}




\begin{tabular}{|c|c|c|c|}
\hline \multicolumn{4}{|c|}{$\begin{array}{c}\text { TABLE B-1: } \\
\text { RANKED SET SAMPLING GAMMA MEASUREMENTS } \\
\text { SANTA SUSANA FIELD LABORATORY } \\
\text { VENTURA COUNTY, CALIFORNIA }\end{array}$} \\
\hline \multirow{2}{*}{$\begin{array}{c}\text { Location } \\
\text { Northing, Easting/Area }\end{array}$} & Ranked Set Sampling & Gamma & \multirow{2}{*}{$\begin{array}{c}\text { Sample } \\
\text { Select } / \text { ID } \\
\text { L=Low } \\
\text { M=Medium } \\
\text { H=High }\end{array}$} \\
\hline & Cycle-Set-Map Code ${ }^{a}$ & cpm & \\
\hline \multicolumn{4}{|c|}{ Group 1 (continued) } \\
\hline $3789411,342314 / 4614$ & $4-3-3 \bullet$ & 6663 & H/S004 \\
\hline \multicolumn{4}{|c|}{ Group 2} \\
\hline $3789651,342965 / 4583$ & $1-1-1=$ & 5330 & L/S013 \\
\hline $3789656,342947 / 4583$ & $1-1-2 \square$ & 6096 & $\mathrm{~L}$ \\
\hline $3789739,343017 / 4583$ & $1-1-1=$ & 5970 & $\mathrm{~L}$ \\
\hline $3789728,343017 / 4583$ & $1-2-1 \Delta$ & 5563 & $\mathrm{M}$ \\
\hline $3789752,343053 / 4583$ & $1-2-2 \Delta$ & 6818 & $\mathrm{M}$ \\
\hline $3789206,342123 / 4059$ & $1-2-3 \Delta$ & 5682 & M/S020 \\
\hline $3789701,343023 / 4583$ & $1-3-3 \bullet$ & 7665 & H/S014 \\
\hline $3789737,343030 / 4583$ & $1-3-2 \bullet$ & 5905 & $\mathrm{H}$ \\
\hline $3789206,342149 / 4059$ & $1-3-1 \bullet$ & 5405 & $\mathrm{H}$ \\
\hline $3789709,342983 / 4583$ & $2-1-3=$ & 5861 & $\mathrm{~L}$ \\
\hline $3789740,343056 / 4583$ & $2-1-2$ & 5892 & $\mathrm{~L}$ \\
\hline $3789239,342204 / 4059$ & $2-1-1$ & 5178 & L/S016 \\
\hline $3789677,342949 / 4583$ & $2-2-2 \Delta$ & 6070 & $\mathrm{M}$ \\
\hline $3789234,342192 / 4059$ & $2-2-3 \Delta$ & 4852 & $\mathrm{M}$ \\
\hline $3789255,342180 / 4059$ & $2-2-1 \Delta$ & 4937 & M/S018 \\
\hline $3789682,342950 / 4583$ & $2-3-2 \bullet$ & 6232 & H/S015 \\
\hline $3789698,342967 / 4583$ & $2-3-1 \bullet$ & 5890 & $\mathrm{H}$ \\
\hline $3789210,342161 / 4059$ & $2-3-3 \bullet$ & 5277 & $\mathrm{H}$ \\
\hline $3789735,343007 / 4583$ & $3-1-1$ & 5878 & $\mathrm{~L}$ \\
\hline $3789238,342202 / 4059$ & $3-1-3$ & 5120 & $\mathrm{~L}$ \\
\hline $3789243,342180 / 4059$ & $3-1-2$ & 5050 & L/S017 \\
\hline $3789233,342177 / 4059$ & $3-2-2 \Delta$ & 4979 & $\mathrm{M}$ \\
\hline $3789248,342157 / 4059$ & $3-2-3 \Delta$ & 5134 & M/S019 \\
\hline $3789268,342149 / 4059$ & $3-2-1 \Delta$ & 5472 & $\mathrm{M}$ \\
\hline $3789194,342134 / 4059$ & $3-3-3$ & 5511 & H/S021 \\
\hline $3789215,342158 / 4059$ & $3-3-1 \bullet$ & 5252 & $\mathrm{H}$ \\
\hline $3789261,342159 / 4059$ & $3-3-2$ & 5245 & $\mathrm{H}$ \\
\hline
\end{tabular}

${ }^{a}$ Refer to Figures 4 and 5.

bSample select code specifies which location is sampled for a given cycle/set based on the gamma count rate. 


\begin{tabular}{|c|c|c|c|c|}
\hline \multicolumn{5}{|c|}{$\begin{array}{c}\text { RADIONUCLIDE CONCENTRATIONS IN SOIL SAMPLES } \\
\text { SANTA SUSANA FIELD LABORATORY } \\
\text { VENTURA COUNTY, CALIFORNIA }\end{array}$} \\
\hline \multirow{2}{*}{$\begin{array}{l}\text { Sample } \\
\text { ID/Area }\end{array}$} & \multirow{2}{*}{$\begin{array}{l}\text { Coordinate } \\
\text { (North, East) }\end{array}$} & \multicolumn{2}{|c|}{$\begin{array}{l}\text { Radionuclide Concentration } \\
\text { (pCi/g) }\end{array}$} & \multirow[t]{2}{*}{ SOR } \\
\hline & & Cs-137 & Eu-152 & \\
\hline \multicolumn{5}{|c|}{ Group 1: Areas 4023, 4028, 4030, 4363, and 4614} \\
\hline S0001/4028 & $3789376 \mathrm{~N}, 342357 \mathrm{E}$ & $-0.04 \pm 0.03^{b}$ & $-0.06 \pm 0.06$ & -0.03 \\
\hline S0002/4028 & $3789388 \mathrm{~N}, 342370 \mathrm{E}$ & $0.00 \pm 0.03$ & $0.03 \pm 0.07$ & 0.01 \\
\hline S0003/4028 & 3789393N, 342352E & $0.01 \pm 0.02$ & $0.01 \pm 0.04$ & 0.01 \\
\hline S0004/4614 & 3789411N, 342314E & $0.05 \pm 0.04$ & $-0.05 \pm 0.05$ & -0.01 \\
\hline S0005/4614 & $3789416 \mathrm{~N}, 342320 \mathrm{E}$ & $0.08 \pm 0.04$ & $-0.02 \pm 0.06$ & 0.01 \\
\hline S0006/4023 & 3789323N, 342571E & $-0.02 \pm 0.02$ & $-0.04 \pm 0.04$ & -0.02 \\
\hline S0007/4023 & $3789323 \mathrm{~N}, 342577 \mathrm{E}$ & $0.00 \pm 0.03$ & $0.02 \pm 0.06$ & 0.01 \\
\hline S0008/4023 & $3789321 \mathrm{~N}, 342580 \mathrm{E}$ & $0.01 \pm 0.03$ & $-0.05 \pm 0.09$ & -0.02 \\
\hline S0009/4030 & 3789417N, 342803E & $0.01 \pm 0.02$ & $0.01 \pm 0.04$ & 0.01 \\
\hline S0010/4030 & $3789415 \mathrm{~N}, 342808 \mathrm{E}$ & $0.01 \pm 0.03$ & $-0.02 \pm 0.07$ & -0.01 \\
\hline S0011/4363 & 3788798N, 342154E & $-0.01 \pm 0.03$ & $-0.05 \pm 0.06$ & -0.02 \\
\hline S0012/4363 & $3788780 \mathrm{~N}, 342152 \mathrm{E}$ & $0.04 \pm 0.03$ & $-0.05 \pm 0.05$ & -0.01 \\
\hline \multicolumn{5}{|c|}{ Group 2: Areas 4059 and 4583} \\
\hline S0013/4583 & $3789651 \mathrm{~N}, 342965 \mathrm{E}$ & $0.00 \pm 0.03$ & $-0.02 \pm 0.06$ & -0.01 \\
\hline S0014/4583 & $3789701 \mathrm{~N}, 343023 \mathrm{E}$ & $-0.01 \pm 0.03$ & $0.03 \pm 0.05$ & 0.01 \\
\hline S0015/4583 & $3789682 \mathrm{~N}, 342950 \mathrm{E}$ & $0.12 \pm 0.03$ & $-0.03 \pm 0.05$ & 0.01 \\
\hline S0016/4059 & $3789239 \mathrm{~N}, 342204 \mathrm{E}$ & $-0.01 \pm 0.03$ & $-0.06 \pm 0.05$ & -0.02 \\
\hline S0017/4059 & $3789243 \mathrm{~N}, 342180 \mathrm{E}$ & $0.01 \pm 0.04$ & $-0.04 \pm 0.06$ & -0.01 \\
\hline S0018/4059 & $3789255 \mathrm{~N}, 342180 \mathrm{E}$ & $0.02 \pm 0.02$ & $-0.03 \pm 0.05$ & -0.01 \\
\hline S0019/4059 & $3789248 \mathrm{~N}, 342157 \mathrm{E}$ & $0.00 \pm 0.02$ & $-0.05 \pm 0.06$ & -0.02 \\
\hline S0020/4059 & $3789206 \mathrm{~N}, 342123 \mathrm{E}$ & $0.06 \pm 0.04$ & $-0.03 \pm 0.07$ & 0.00 \\
\hline S0021/4059 & 3789194N, 342134E & $0.12 \pm 0.06$ & $0.05 \pm 0.06$ & 0.04 \\
\hline
\end{tabular}

${ }^{a}$ Refer to Figures 6 and 7.

bUncertainties are total propagated uncertainties, based on the $95 \%$ confidence interval. 


\begin{tabular}{|c|c|}
\hline \multicolumn{2}{|c|}{$\begin{array}{l}\text { TABLE B-3: } \\
\text { SOIL GUIDELINE RELEASE LIMITS }\end{array}$} \\
\hline Radionuclide & $\begin{array}{l}\text { Soil Guidelines } \\
\text { (pCi/g) }\end{array}$ \\
\hline Am-241 & 5.44 \\
\hline Ba-133 & 16.4 \\
\hline Co-60 & 1.94 \\
\hline Cs-134 & 3.33 \\
\hline Cs-137 & 9.20 \\
\hline Eu-152 & 4.51 \\
\hline Eu-154 & 4.11 \\
\hline $\mathrm{Fe}-55$ & 629,000 \\
\hline $\mathrm{H}-3$ & 31,900 \\
\hline $\mathrm{K}-40$ & 27.6 \\
\hline $\mathrm{Mn}-54$ & 6.11 \\
\hline $\mathrm{Na}-22$ & 2.31 \\
\hline $\mathrm{Ni}-59$ & 151,000 \\
\hline $\mathrm{Ni}-63$ & 55,300 \\
\hline $\mathrm{Pu}-238$ & 37.2 \\
\hline $\mathrm{Pu}-239$ & 33.9 \\
\hline $\mathrm{Pu}-240$ & 33.9 \\
\hline $\mathrm{Pu}-241$ & 230 \\
\hline $\mathrm{Pu}-242$ & 35.5 \\
\hline Ra-226 & 5 and $15^{a}$ \\
\hline Sr-90 & 36 \\
\hline Th-228 & 5 and $15^{a}$ \\
\hline Th-232 & 5 and $15^{a}$ \\
\hline $\mathrm{U}-234$ & $30^{\mathrm{b}}$ \\
\hline $\mathrm{U}-235$ & $30^{\mathrm{b}}$ \\
\hline $\mathrm{U}-238$ & $35^{b}$ \\
\hline
\end{tabular}

aDOE Order 5400.5 (DOE 1993) limits are $5 \mathrm{pCi} / \mathrm{g}$ averaged over the first $15 \mathrm{~cm}$ of soil depth and $15 \mathrm{pCi} / \mathrm{g}$ averaged over $15 \mathrm{~cm}$ layers below the top $15 \mathrm{~cm}$.

${ }^{\mathrm{b}}$ Generally, more conservative NRC limits for Uranium isotopes are proposed.

"Rocketdyne Report N001SRR140131, “Approved Sitewide Release Criteria for Remediation of Radiological Facilities at SSFL”, February, 1999. 
APPENDIX C

MAJOR INSTRUMENTATION 


\section{APPENDIX C}

\section{MAJOR INSTRUMENTATION}

The display of a specific product is not to be construed as an endorsement of the product or its manufacturer by the author or his employer.

\section{SCANNING AND MEASUREMENT INSTRUMENT/DeTECTOR COMBINATIONS}

\section{$\underline{\text { Gamma }}$}

Victoreen NaI Scintillation Detector Model 489-55, Crystal: $3.2 \mathrm{~cm}$ x $3.8 \mathrm{~cm}$

(Victoreen, Cleveland, $\mathrm{OH}$ )

coupled to:

Ludlum Ratemeter-scaler Model 2221

(Ludlum Measurements, Inc., Sweetwater, TX)

coupled to:

Trimble GeoXH Receiver and Data Logger (Trimble Navigation Limited, Sunnyvale, CA)

\section{Laboratory Analytical Instrumentation}

High Purity Extended Range Intrinsic Detector

CANBERRA/Tennelec Model No: ERVDS30-25195

(Canberra, Meriden, CT)

Used in conjunction with:

Lead Shield Model G-11

(Nuclear Lead, Oak Ridge, TN) and

Multichannel Analyzer

DEC ALPHA Workstation

(Canberra, Meriden, CT)

High Purity Extended Range Intrinsic Detector

Model No. GMX-45200-5

(AMETEK/ORTEC, Oak Ridge, TN)

used in conjunction with:

Lead Shield Model SPG-16-K8

(Nuclear Data)

Multichannel Analyzer

DEC ALPHA Workstation

(Canberra, Meriden, CT) 


\section{Laboratory Analytical Instrumentation (continued)}

High-Purity Germanium Detector

Model GMX-30-P4, 30\% Eff.

(AMETEK/ORTEC, Oak Ridge, TN)

Used in conjunction with:

Lead Shield Model G-16

(Gamma Products, Palos Hills, IL) and

Multichannel Analyzer

DEC ALPHA Workstation

(Canberra, Meriden, CT) 


\section{APPENDIX D \\ SURVEY AND ANALYTICAL PROCEDURES}




\section{APPENDIX D \\ SURVEY AND ANALYTICAL PROCEDURES}

\section{Project Health ANd SAFETy}

The proposed survey and sampling procedures were evaluated to ensure that any hazards inherent to the procedures themselves were addressed in current job hazard analyses. Additionally, upon arrival on site, a walk-down of the site was performed to identify hazards present and a pre-job integrated safety management checklist was completed and discussed with field personnel. All survey and laboratory activities were conducted in accordance with ORISE health and safety and radiation protection procedures.

\section{Calibration AND Quality Assurance}

Calibration of all field and laboratory instrumentation was based on standards/sources, traceable to NIST.

Analytical and field survey activities were conducted in accordance with procedures from the following documents of the Environmental Survey and Site Assessment Program:

- $\quad$ Survey Procedures Manual, (January 2008)

- $\quad$ Laboratory Procedures Manual, (March 2008)

- Quality Program Manual, (November 2007)

The procedures contained in these manuals were developed to meet the requirements of Department of Energy (DOE) Order 414.1C and the U.S. Nuclear Regulatory Commission Quality Assurance Manual for the Office of Nuclear Material Safety and Safeguards and contain measures to assess processes during their performance.

Quality control procedures include:

- Daily instrument background and check-source measurements to confirm that equipment operation is within acceptable statistical fluctuations. 
- $\quad$ Participation in MAPEP, NRIP, and ITP Laboratory Quality Assurance Programs.

- Training and certification of all individuals performing procedures.

- $\quad$ Periodic internal and external audits

\section{SuRVey Procedures}

\section{$\underline{\text { Surface Scans }}$}

A $\mathrm{NaI}$ scintillation detector was used to scan for elevated gamma radiation. Identification of elevated radiation levels was based on increases in the audible signal from the recording and/or indicating instrument. Additionally, the detectors were coupled to GPS units with data loggers enabling real-time recording in one- or two-second intervals of both geographic position and the gamma count rate. Position and gamma count rate data files were transferred to a computer system, positions differentially corrected, and the results plotted on geo-referenced aerial photographs.

Positional accuracy was within 0.5 meters at the $95^{\text {th }}$ percentile.

The scan minimum detectable concentrations for the $\mathrm{NaI}$ scintillation detectors were $10.4 \mathrm{pCi} / \mathrm{g}$ for Cs-137, as provided in NUREG-1507, and approximately 5.8 pCi/g for Eu-152 .

\section{Soil Sampling}

Approximately 0.5 to $1 \mathrm{~kg}$ of soil was collected at each sample location. Collected samples were placed in a plastic bag, sealed, and labeled in accordance with ORISE survey procedures.

\footnotetext{
1 The scan MDC for Eu-152 was estimated based on empirical calculations for NaI response versus gamma energy provided in Decommissioning Health Physics: A Handbook for MARSSIM Users, E.W. Abelquist; 2001.
} 


\section{RADIOLOGICAL ANALYSIS}

\section{Gamma Spectroscopy}

Samples of soil were dried, mixed, crushed, and/or homogenized as necessary, and a portion sealed in a 0.5-liter Marinelli beaker or other appropriate container. The quantity placed in the beaker was chosen to reproduce the calibrated counting geometry. Net material weights were determined and the samples counted using intrinsic germanium detectors coupled to a pulse height analyzer system. Background and Compton stripping, peak search, peak identification, and concentration calculations were performed using the computer capabilities inherent in the analyzer system. All total absorption peaks (TAP) associated with the radionuclides of concern were reviewed for consistency of activity. TAPs used for determining the activities of radionuclides of concern and the typical associated MDCs for a one-hour count time were:

\begin{tabular}{|c|c|c|}
\hline \hline Radionuclide & TAP $\mathbf{( M e V})$ & MDC (pCi/g) \\
\hline \hline Eu-152 & $0.344 \mathrm{MeV}$ & 0.07 \\
\hline Cs-137 & $0.662 \mathrm{MeV}$ & 0.03 \\
\hline
\end{tabular}

Spectra were also reviewed for other identifiable TAPs.

\section{DETECTION LiMits}

Detection limits, referred to as minimum detectable concentrations, were based on 3 plus 4.65 times the standard deviation of the background count $\left[3+\left(4.65(\mathrm{BKG})^{1 / 2}\right)\right]$. Because of variations in background levels, measurement efficiencies, and contributions from other radionuclides in samples, the detection limits differ from sample to sample and instrument to instrument. 